\title{
Numerical study on the origins and the forcing mechanism of the phosphate in upwelling areas off the coast of Zhejiang province, China in summer
}

\author{
Dezhou Yang a,b, Baoshu Yin ${ }^{\text {a,b,* }}{ }^{\text {, Junchuan Sun }}{ }^{\text {a,b,c }}$, Yong Zhang ${ }^{\text {d }}$ \\ a Key Laboratory of Ocean Circulation and Waves, Chinese Academy of Sciences, Qingdao 266071, China \\ ${ }^{\mathrm{b}}$ Institute of Oceanology, Chinese Academy of Sciences, Qingdao 266071, China \\ c University of Chinese Academy of Sciences, Beijing 100049, China \\ d Key Laboratory of Coastal Zone Environmental Processes, Yantai Institute of Coastal Zone Research, Chinese Academy of Sciences, Yantai 264003, China
}

\section{A R T I C L E I N F O}

\section{Article history:}

Received 22 January 2013

Received in revised form 5 April 2013

Accepted 9 April 2013

Available online 18 April 2013

\section{Keywords:}

Western boundary currents

Ocean circulation

East China Sea

Phosphates

Upwelling

China, Zhejiang province

\begin{abstract}
A B S T R A C T
Off the coast of Zhejiang province, China, algal blooms are frequently observed where the phosphate seems to be an essential ingredient to dominate the growth of the phytoplankton in summer. Therefore, the observed high phosphate distributions off the coast of Zhejiang are closely examined to find out the dominant phosphate origin as well as the underlying forcing mechanism in summer. The observed phosphate distribution has been faithfully reproduced by our numerical model based on the Regional Ocean model System (ROMS). Then, on the basis of the numerical experiments as well as the observations, we propose that the phosphate off the coast of Zhejiang mainly originates from the deep sea water in a special area $\left(122.1^{\circ} \mathrm{E}-\right.$ $\mathrm{z} 122.5^{\circ} \mathrm{E}, 130 \mathrm{~m}-300 \mathrm{~m}$ deep) along $24.9^{\circ} \mathrm{N}$ northeast of Taiwan. Also, the forcing mechanism is clearly illustrated. In the bottom water of southern East China Sea, huge phosphate is continuously transported to the area off the coast of Zhejiang by a nearshore Kuroshio branch current which links the phosphate-rich deep sea water to the bottom water off the coast of Zhejiang. Then, off the coast of Zhejiang the transported phosphate-rich water is further upwelled to the surface water due to an upwelling just off the coast of Zhejiang. Then, the upwelled phosphate-rich water is transported offshore in the surface water by the northeastward flowing Taiwan Warm Current, forming a high phosphate tongue which can be easily utilized by the phytoplankton and then immediately explains the observed high chlorophyll tongue off the coast of Zhejiang. Crown Copyright (c) 2013 Published by Elsevier B.V. All rights reserved.
\end{abstract}

\section{Introduction}

The domain off the coast of Zhejiang province, China (see the shaded area in Fig. 1) has been increasingly noted for the frequently reported algal bloom events in its surface water (Chen et al., 2004; Wang and $\mathrm{Wu}, 2009$ ) and the hypoxia in its bottom water (Chen et al., 2007; Li et al., 2002; Wei et al., 2007; Zhu et al., 2011). In addition, the upwelling in this area is very strong (Hu, 1984, 1994; Lv et al., 2006; Qiao et al., 2006; Wang and Wang, 2007a), and the famous Zhoushan fishing ground also lies in this area. The high fishery production in this area is likely induced by the high primary production in the water since the ecosystem is powered by primary production (Gong et al., 2003). Furthermore, this high primary production is closely related to the nutrient enrichment in the euphotic zone caused by upwelling and the discharge of Changjiang River, the largest river in Asia in terms of volume discharge (see Fig. 1) (Chen et al., 2004; Gong et al.,

\footnotetext{
* Corresponding author at: Institute of Oceanology, Chinese Academy of Sciences, 7 Nanhai Road, Qingdao 266071, China. Tel.: +86 532 82898931; fax: + 86532 82898502.

E-mail address: bsyin@qdio.ac.cn (B. Yin).
}

2011; Zhang et al., 2007, 2010). However, the high primary production in the surface water likely in turn leads to the hypoxia in the bottom water, because of the large oxygen demand from microbial decay of sinking organic particles which derives from the combination of the death of the local phytoplankton in the surface water, and the organic particles advected by Changjiang River (Chen et al., 2006; Gong et al., 1996; Stramma et al., 2008; Zhang et al., 2010). In addition, oxygen is also consumed during reoxidation of reduced constituents such as sulfide and methane in the bottom water (Zhang et al., 2010). Unfortunately, the coastal hypoxia usually damages the coastal ecosystem and affects fisheries via food web interactions (Zhu et al., 2011). Therefore, the high primary production in the area off the coast of Zhejiang plays an important role in the coastal ecosystem. On the other hand, the rate of primary production was regulated by the availability of the nutrients, especially phosphate, from summer to autumn (Gong et al., 2003). Furthermore, it has been suggested that nutrients may be one of the most important controlling factors for phytoplankton growth in the East China Sea (ECS, see Fig. 1) (Chen et al., 2006; Gong et al., 1996). In addition, the growth of phytoplankton limited by phosphate has been observed in the ECS, especially in the Changjiang River plume where the ratio of N/P reaches as high as 38.2 in August 2003 and the water was enriched in nitrate and silicate but depleted in 


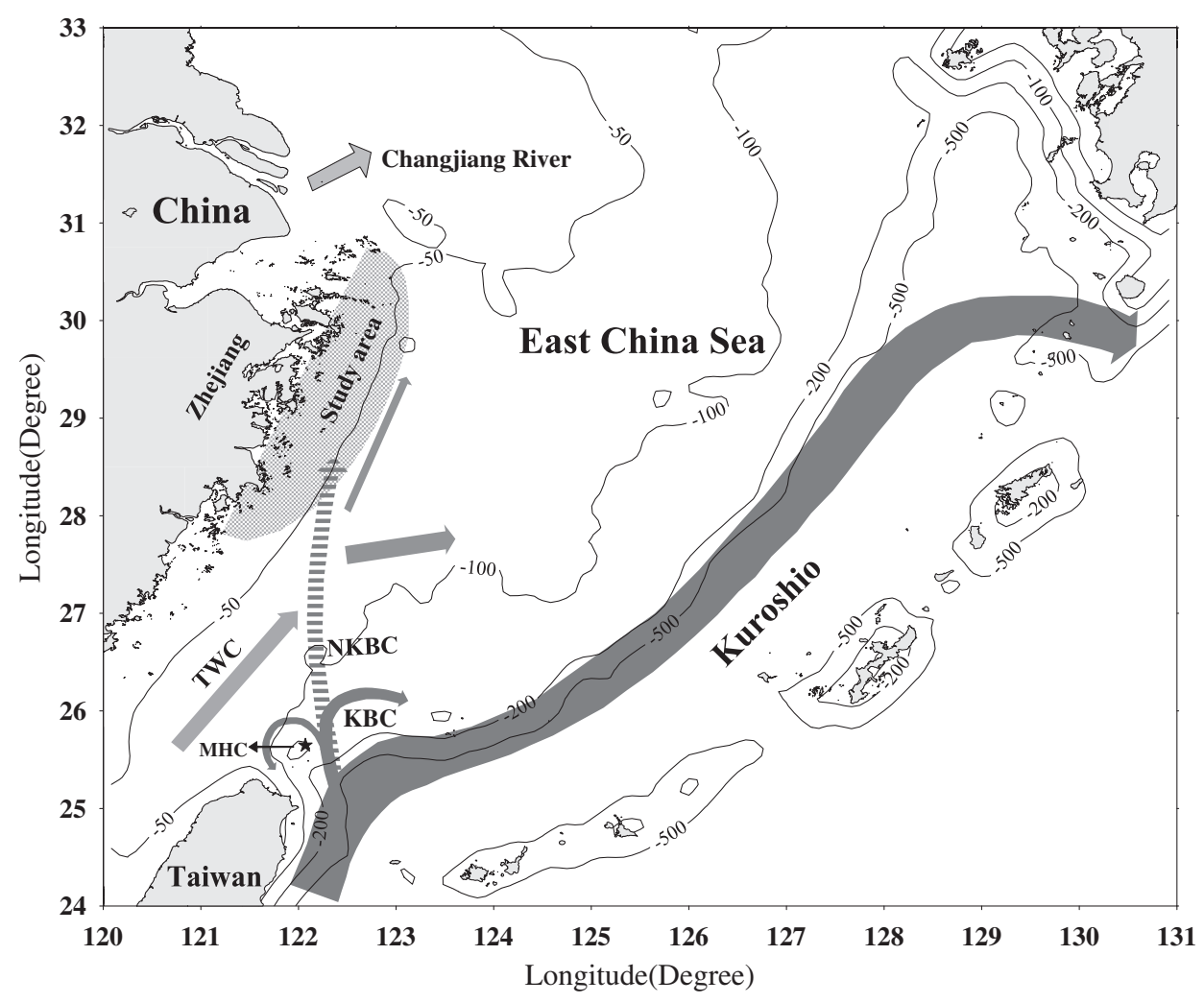

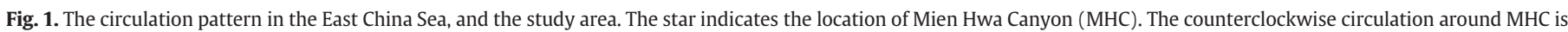

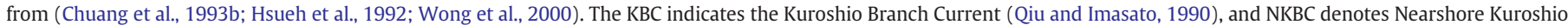

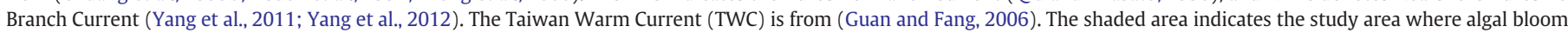

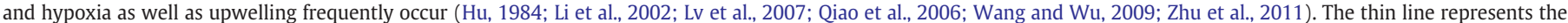
isobaths of $50 \mathrm{~m}, 100 \mathrm{~m}, 200 \mathrm{~m}$, and $500 \mathrm{~m}$, respectively.

phosphate (Chen et al., 2004, 2006; Gong et al., 1996). Also, Chen et al. (2006) reported that the mean ratio of N/P on the ECS continental shelf was $22.8 \pm 15.0$ and $22.0 \pm 14.8$ in June and August 2003 respectively, which suggested that the phosphate might regulate phytoplankton in summer because the phytoplankton consumes $\mathrm{N}$ and $\mathrm{P}$ with a Redfield ratio $\mathrm{N}: \mathrm{P}=16: 1$. In other words, the supply of dissolved inorganic phosphorus from the Changjiang River, the upwelling and the open sea may fuel the high primary production off the coast of Zhejiang in summer (Gong et al., 2003). Therefore, the phosphate becomes crucial to maintaining the phytoplankton production in the area off the coast of Zhejiang in summer.

However, the phosphate concentration off the coast of Zhejiang is subject to a complicated ocean circulation pattern in summer which could be closely related to the discharge of Changjiang River, Taiwan Warm Current (TWC, see Fig. 1) (Guan and Fang, 2006), the Nearshore Kuroshio Branch Current (NKBC, see Fig. 1) (Yang et al., 2011, 2012), and their interactions. Chung et al. (2001) reported that the phosphate contribution from the Taiwan Strait to the ECS in summer was 8-17 times larger than that from the Changjiang River. On the other hand, it has also been reported that the intrusion of Kuroshio subsurface water is the major phosphate source in the ECS (Chen, 1996; Chen and Wang, 1999; Fang, 2004; Liu et al., 2000). However, the amount of phosphate from Kuroshio subsurface water, which can be transported by NKBC to the upwelling area off the coast of Zhejiang, remains unclear. Therefore, one question immediately arises: how much phosphate in the Kuroshio subsurface water, in the discharge of Changjiang River, and in the Taiwan Strait water can be transported, respectively, into the area off the coast of Zhejiang where the alga bloom and hypoxia frequently occur (Chen et al., 2004, 2007; Li et al., 2002; Wang and Wu, 2009; Wei et al., 2007; Zhu et al., 2011)? Moreover, among the Changjiang River, NKBC, and TWC which one is dominant in this area? Furthermore, the underlying processes and mechanisms remain to be elucidated. On the other hand, Chen (2008) pointed out that no updated estimates of nutrient fluxes through the Taiwan Strait have been made, and fluxes through the Taiwan Strait need revision, which may alter the ECS nutrient budgets to a certain extent. Therefore, this paper is organized to carefully address these questions on the basis of numerical simulations and field observations.

\section{Material and method}

In order to carefully clarify the above questions, a series of experiments have been conducted on the basis of field observations as well as Regional Ocean Model System (ROMS) (Shchepetkin and McWilliams, 2005) which has been successfully implemented in the ECS and carefully verified by comparisons with field data such as observational ocean current, salinity and temperature (Yang et al., 2011, 2012). Therefore, the well validated Nest2 model (see Nest2 in Fig. 2 of (Yang et al., 2011)) has been directly applied to the simulation of the phosphate transport in the ECS. The field data are compared with model results in order to verify the phosphate model.

\subsection{Field data}

A summer and a spring cruise were conducted in the ECS by the Xiamen University along four transects (KP, DH5, DH3 and DH2, see Fig. 2) where KP comprises KP01-13, DH5 comprises DH51-DH54, DH3 comprises DH31-35, DH2 comprises DH21-26. Phosphate samples were carefully collected in the ECS with Niskin bottles which were mounted onto a Rosette sampling assembly along with a conductivitytemperature-depth recorder (Sea-Bird SBE911). Then, the phosphate samples were stored at $-20{ }^{\circ} \mathrm{C}$ until were analyzed. Next, the phosphate concentration was measured using typical spectrophotometric methods where the detection limit of phosphate was $0.03 \mu \mathrm{mol} \mathrm{dm}{ }^{-3}$ 


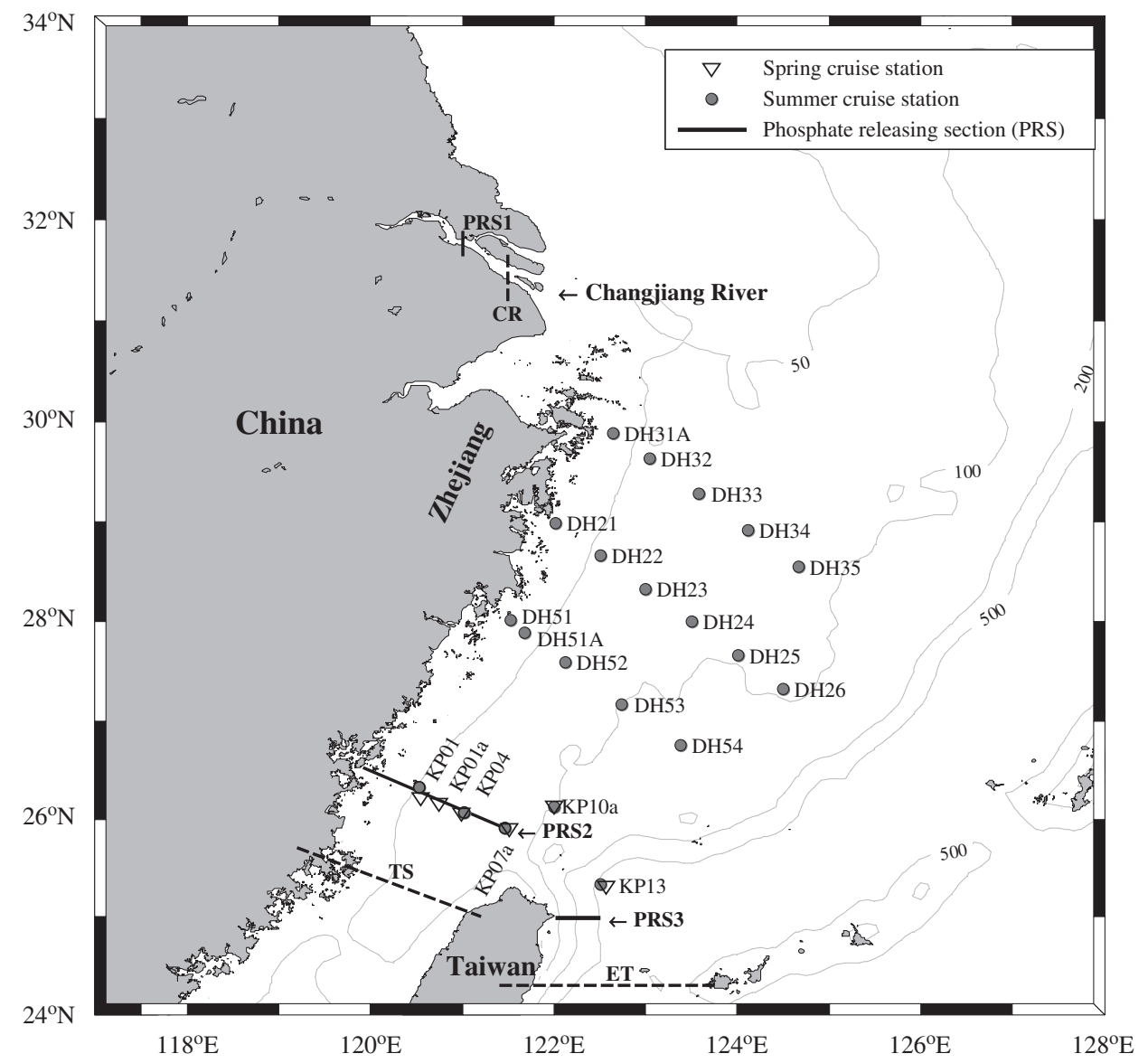

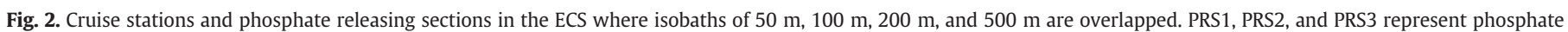

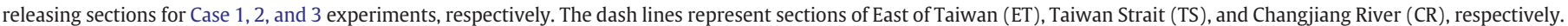

(Han et al., 2012). For the details of the phosphate measurement, please refer to the paper (Han et al., 2012). The summer cruise is conducted during the period between 15 August and 2 September 2009, while the spring cruise is conducted from 30 May through 9 June along the same transects as that of the summer cruise (see Fig. 2).

\subsection{Model configuration}

The model domain of Nest 2 extends from $116^{\circ} \mathrm{E}$ to $136^{\circ} \mathrm{E}$ in the longitude direction and from $21^{\circ} \mathrm{N}$ to $41^{\circ} \mathrm{N}$ in the latitude direction, respectively. In addition, the Nest 2 model, with a fine horizontal resolution of $\sim 8 \mathrm{~km}$, properly covers the ECS and has been embedded in a coarse Nest1 model (see Nest1 in Fig. 2 of (Yang et al., 2011)), which almost covers the whole Pacific Ocean, has been run for 40 year for spin-up, and then been run for another 12 years for hindcast from 1 January 2000 through 1 January 2012 (Yang et al., 2012). Next, the high-resolution Nest2 model is initialized with the spin-up state of Nest1 model, and then has been run for 10 model years for spin-up as well as another 12 model years for hindcast (2000-2011). It is worthwhile noting that the run of Nest2 is forced at the boundaries by the interpolated 5 days mean fields from Nest 1 model, and additionally by tidal velocities and free-surface heights from 10 tide constituents of the TPXO7 (Egbert and Erofeeva, 2002) as well as the river discharges. For further information of model configuration, please refer to our earlier papers (Yang et al., 2011, 2012). However, for present purposes we just use the Nest2 model to simulate the phosphate transport in the ECS during a relatively short period of time in 2009.

Although the hydrographic result of Nest 2 model has been proven successful, there are some areas where the phosphate transport model should be illustrated. In this paper, the transport of phosphate is primarily controlled by the following equation:

$\frac{\partial P}{\partial t}+\vec{V} \cdot \nabla P=-\frac{\partial}{\partial z}\left(-K_{P} \frac{\partial P}{\partial z}-\nu_{P} \frac{\partial P}{\partial z}\right)+D_{P}+S_{P}$

where $P$ is phosphate concentration, $D_{P}$ represents horizontal diffusive term, $\nu_{P}$ means molecular diffusivity which is negligible compared with turbulent diffusivity $\left(K_{P}\right), S_{P}$ denotes source terms such as phosphate input from rivers or from the open boundaries, and $V$ is the ocean current computed from the Nest 2 model.

On the other hand, there are biogeochemical processes which could influence the phosphate concentration in the area off the coast of Zhejiang. As yet, off the coast of Zhejiang it is too difficult to accurately simulate theses biogeochemical processes in a physicalbiogeochemical-ecosystem model due to the absence of field observations, because the accurate parameterization formulas of biogeochemical processes are closely based on the huge amount of field observations. Therefore, in this paper the phosphate contribution from the biogeochemical processes is excluded from the numerical simulation of the phosphate transport. In other words, the phosphate is conservative and only the dissolved inorganic phosphorus is included in Nest2 model. Obviously, the advantage of this treatment of conservative phosphate outweighed the apparent disadvantage, because the influence of ocean current on the phosphate concentration can be solely distinguished from the observational composite phosphate concentration which includes not only the contributions from biogeochemical processes, but also that from the hydrodynamic processes such as advection and diffusion of phosphate. Hereinafter, whenever the phosphate is 
used, it means dissolved inorganic phosphorus $\left(\mathrm{PO}_{4}^{3-}\right)$. The simulation duration of the phosphate transport model is from 30 May to 2 September 2009 (see Fig. 3). Furthermore, in all of the numerical experiments in this paper the phosphate concentration on 30 May 2009 is initialized with zero, while the ocean current model restarts from a hotfile (a restart file which had been created by a previous run and contained the ocean current, temperature, salinity and sea surface height on 30 May 2009).

\subsection{Open boundary conditions}

In order to identify the process which would directly influence the phosphate budget off the coast of Zhejiang, phosphate transport experiments have been done for four typical cases: Case 1 where only the phosphate input from Changjiang River is considered, Case 2 where the only phosphate input comes from the Taiwan Strait, Case 3 where the only phosphate input is from the Kuroshio, and Control run where the phosphate inputs from the Changjiang River, Taiwan Strait and Kuroshio are all included (see Table 1). Zero-gradient conditions (Marchesiello et al., 2001) are applied to the Nest2 model as the open boundary conditions of phosphate. In this way the direct use of observational phosphate along the four open boundaries is avoided. Neither has phosphate concentration along the four open boundaries been measured, nor could the measurement along the open boundaries be easily

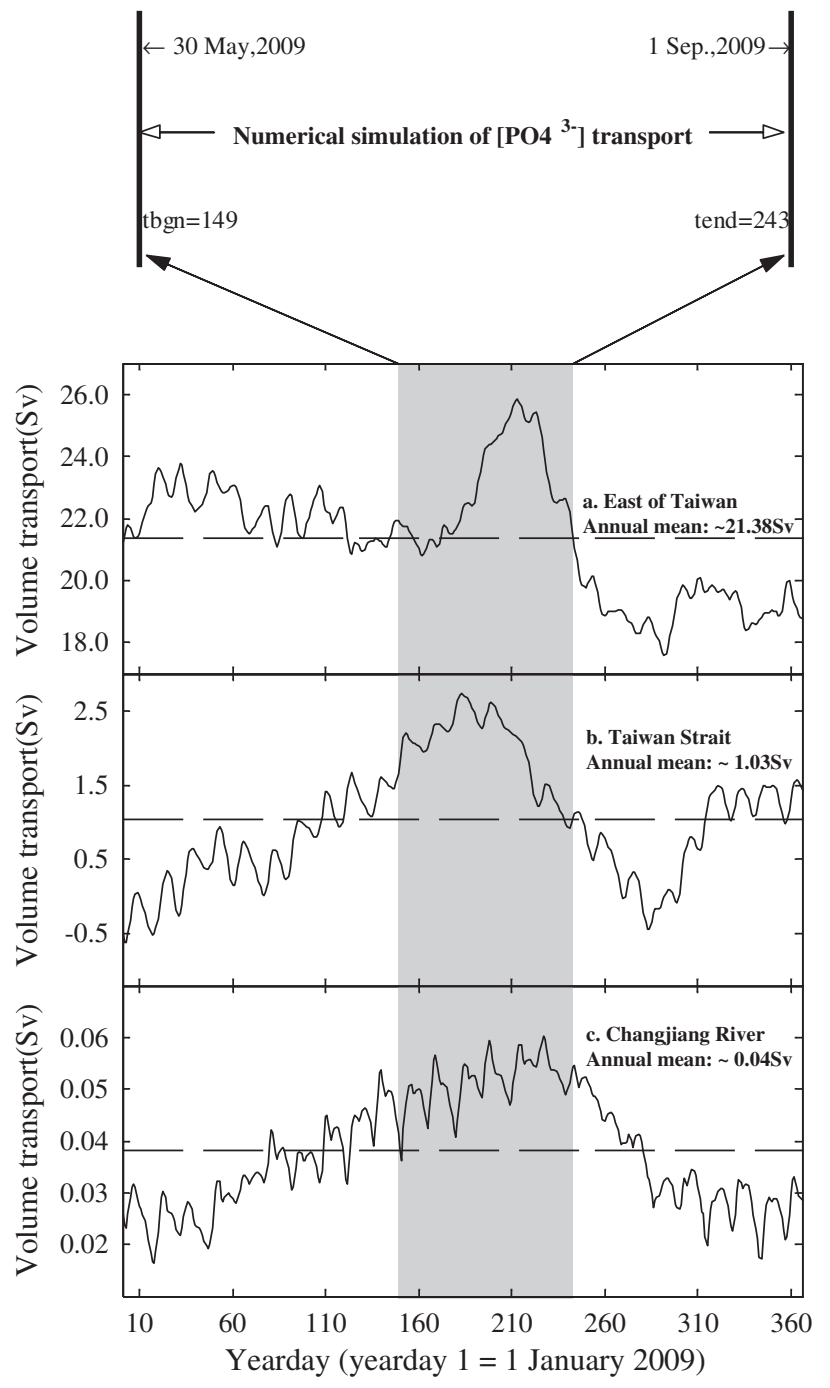

Fig. 3. Modeled volume flux across (a) ET, (b) TS, and (c) CR in 2009 (see ET, TS, and CR in Fig. 2). Simulation duration of phosphate transport experiments is shown in the gray area.
Table 1

Phosphate input experiments.

\begin{tabular}{llll}
\hline & $\begin{array}{l}\text { Phosphate input from } \\
\text { Changjiang River }\end{array}$ & $\begin{array}{l}\text { Phosphate input } \\
\text { from Taiwan Strait }\end{array}$ & $\begin{array}{l}\text { Phosphate input from } \\
\text { east of Taiwan }\end{array}$ \\
\hline $\begin{array}{l}\text { Case 1 } \\
\text { Case 2 }\end{array}$ & $\mathrm{T}$ & $\mathrm{T}$ & \\
Case 3 & & & $\mathrm{T}$ \\
Control run & $\mathrm{T}$ & $\mathrm{T}$ & $\mathrm{T}$ \\
\hline
\end{tabular}

carried on due to the wide spatial range from $21^{\circ} \mathrm{N}$ to $41^{\circ} \mathrm{N}$ as well as the long period from spring through summer. Fortunately, there is a $\mathrm{KP}$ transect (see KP stations in Fig. 2) which is properly across the TWC and Kuroshio; the KP transect is surveyed in spring and summer, respectively. Therefore, the measurements of the phosphate concentration along the KP transect are used as the source of the phosphate from the Taiwan Strait and Kuroshio. In each case this method is shown to perform well.

\section{Case 1. Phosphate input from Changjiang River}

In Case 1, a reasonable constant phosphate concentration of $0.75 \mu \mathrm{mol} \mathrm{dm}{ }^{-3}$ (see Table 1 in (Zhang et al., 2007) and see Figs. 5 and 13 in (Wang et al., 2011)) along the phosphate releasing Section 1 (PRS1, see Fig. 2) has been used to drive the phosphate transport model, because there are no concomitant phosphate measurements across the Changjiang River in the spring and summer cruise. In addition, the phosphate concentration remains constant during the phosphate transport experiment.

\section{Case 2. Phosphate input from Taiwan Strait}

The phosphate distribution along the PRS2 on 30 May 2009 (see Figs. 2 and $4 \mathrm{a}$ ) is initialized with the phosphate concentration at stations KP01, KP01a, KP04 and KP07a (see Fig. 2) in spring cruise. In addition, the phosphate distribution west of KP01 as well as that between the stations is optimally adjusted according to previous studies (see Fig. 7 in (Chung et al., 2001) and Fig. 2 in (Wang and Wang, 2007b)). Similarly, the phosphate distribution along the PRS2 on 1 September 2009 (see Fig. 4b) is given by the field measurements at stations KP01, KP04 and KP07a (see Fig. 2) in summer cruise. Also, the phosphate distribution west of KP01 as well as that between the stations is linearly interpolated from a combination of field measurements in the summer cruise and previous measurements (see Fig. 3 in (Wang and Wang, 2007b), Fig. 9 and Eq. (6) in (Liu et al., 2000), Fig. 4 in (Chung et al., 2001), Fig. 4 in (Chen, 2009), Fig. 7 in (Gong et al., 2003), Fig. 5 in (Chen et al., 2004) and Fig. 3 in (Chen et al., 2006)). In order to consider the temporal variation of the phosphate concentration along the PRS2 during the simulation of the phosphate transport (from 30 May to 1 September 2009), it is assumed that the phosphate concentration along the PRS2 varies according to a linear function (see $P(x, y, t)$ in Eq. (2)).

$$
\left\{\begin{array}{c}
P(x, y, t)=f 1 \times P(x, y, \text { tbgn })+f 2 \times P(x, y, \text { tend }) \quad \text { tbgn } \leq t \leq \text { tend } \\
f 1=(\text { tend }-t) /(\text { tend }- \text { tbgn }) \\
f 2=(t-\text { tbgn }) /(\text { tend }- \text { tbgn }) \\
\text { tbgn }=149(\text { date number of } 30 \text { May } 2009 \text { relative to } 1 \text { Jan. 2009) } \\
\text { tend }=243(\text { date number of } 1 \text { Sep. } 2009 \text { relative to } 1 \text { Jan. 2009) }
\end{array}\right.
$$

where $x$ represents the distance relative to the nearshore end point of PRS2, $y$ denotes the vertical coordinate (water depth), and $t$ means the time. In Case 2 , the $P(x, y, \operatorname{tbgn})$ and $P(x, y$, tend $)$ are actually represented by the phosphate distribution in Fig. $4 \mathrm{a}$ and b, respectively. In addition, Eq. (2) has been exclusively applied to all of the numerical experiments in this paper in order to represent the temporal variation of phosphate concentration along the PRS2 and PRS3. 


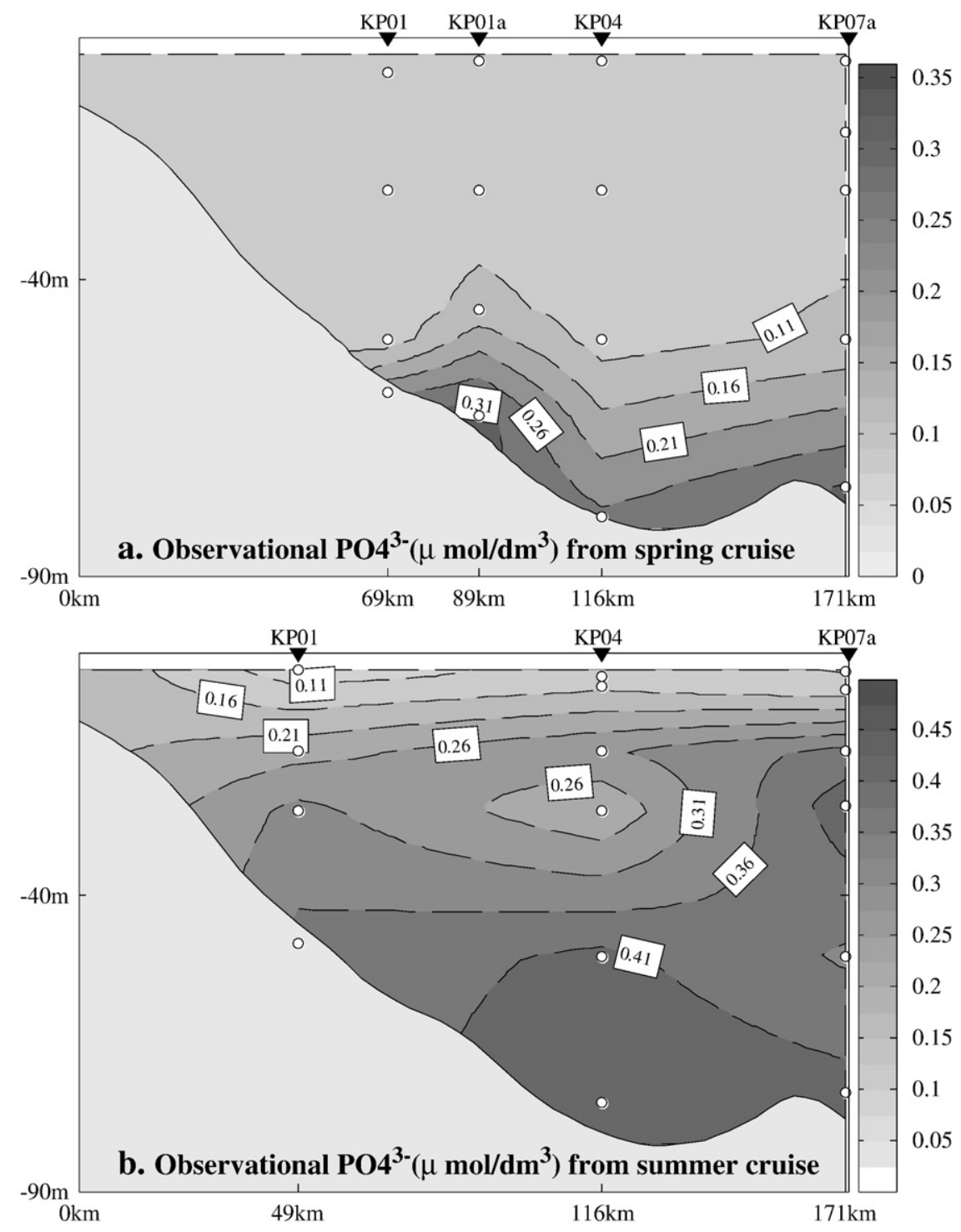

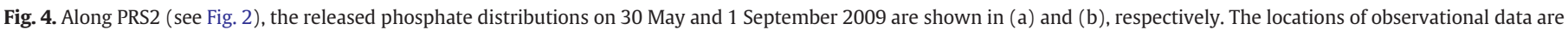
represented by the white dots.

Case 3. Phosphate input from Kuroshio

The phosphate profile at the eastern end point of PRS3 (see Fig. 2) is assumed to remain in a similar vertical shape with the measured phosphate profile at the station KP13 (see Figs. 2, 5a and c), because the two points are sequentially passed through by the mainstream of Kuroshio and the distance between them is small. Next, owing to a lack of observations the phosphate distributions along PRS3 in spring and summer (see Fig. 5a and c) are, respectively, linearly interpolated from field measurements at station KP13 and KP10a (see Figs. 5b, d and 2) as well as previous measurements in spring and summer (see Figs. 7 and 8 in (Wong et al., 1991), Fig. 7 in (Chen et al., 1995), Figs. 2 and 3 in (Gong et al., 1996), Fig. 9 and Eq. (6) in (Liu et al., 2000), Fig. 7 in (Gong et al., 2003), Fig. 5 in (Chen et al., 2004), and Figs. 4 and 5 in (Chen, 2009)). Again, the linear function Eq. (2) is used to calculate the temporal variation of the phosphate concentration along the PRS3 during the simulation of the phosphate transport (from 30 May to 1 September 2009), where the $P(x, y$, tbgn $)$ and $P(x, y$, tend $)$ in Case 3 are exactly represented by the phosphate distribution in Fig. $5 \mathrm{a}$ and $\mathrm{c}$, respectively. In addition, the phosphate concentration across Kuroshio east of Taiwan shows a typical nutrient distribution: concentration depletion in the surface layer and enrichment in the deeper layer (Chen et al., 1995, 2004; Fang, 2004).

\section{Model results}

The model shows strong capability to properly reproduce the ocean currents in the ECS such as the Kuroshio, TWC and Changjiang diluted water (CDW) which are closely related to the phosphate budget off the coast of Zhejiang. As is shown by Fig. 6a, the modeled monthly mean Kuroshio at $15 \mathrm{~m}$ depth in August 2009, properly turns northeastward northeast of Taiwan, and then flows along the shelf break until $\sim 30.5^{\circ} \mathrm{N}$ where it turns eastward and exits the ECS through Tokara Strait. Besides the path of Kuroshio, both the strength and width of it agree very well with the observations (Guan and Fang, 2006; Hu et al., 2008; Ichikawa and Beardsley, 2002; Isobe, 2008). Also markedly shown in Fig. 6a is the TWC, which mainly originates from the Taiwan Strait in summer, and then flows mostly parallel to the coast of China until $\sim 28.5^{\circ} \mathrm{N}$ where it bifurcates into two branches. Its nearshore branch is so weak that the northward flow cannot be easily distinguished from the surface ocean currents, while the mainstream of TWC clearly turns first to east and later to northeast. Finally, the TWC 

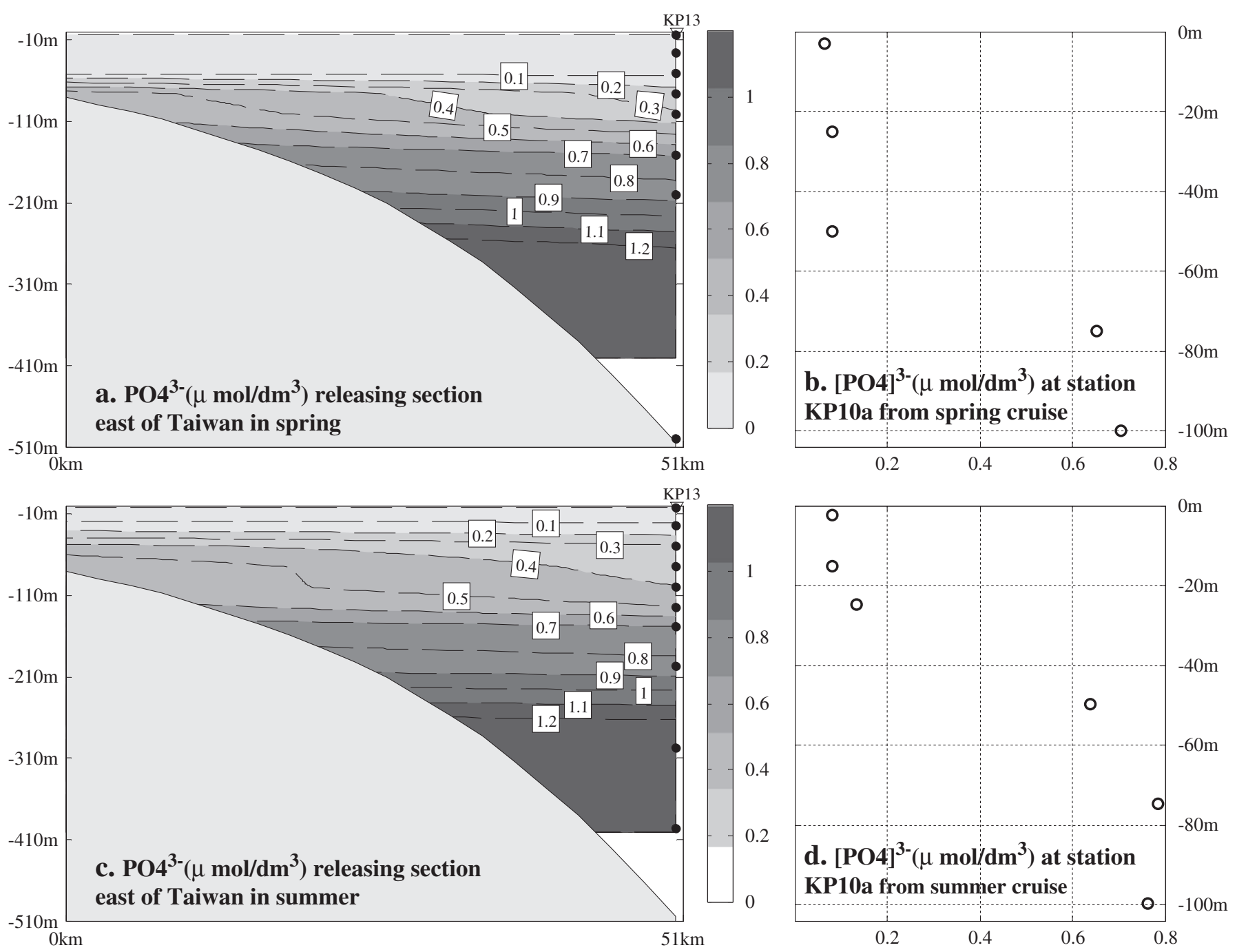

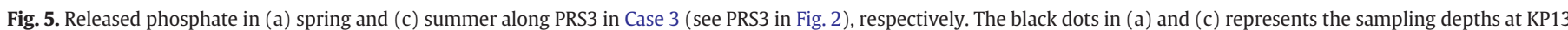
station. The phosphate profiles at station KP10a in spring and summer are shown in (b) and (d), respectively.

can reach as far as Japan Sea passing through Tsushima Strait, though part of it joins in the mainstream of Kuroshio in the ECS. Again, for the TWC the model shows satisfactory agreement with observations (Guan and Fang, 2006; Hu et al., 2010; Isobe, 2008; Su et al., 1994). At the same time, it is also worthwhile noting that the relatively weak southward coastal current immediate south of the Changjiang River (Fan et al., 2011; Kim et al., 2009) is also correctly reproduced. In addition, the ocean current northeast of Taiwan is more clearly shown in an enlarged map (see Fig. 6b), because the correct simulation of ocean current in this area is especially critical to properly reproduce the material exchange between Kuroshio and the ECS. As reported by Wong et al. (2000), the cyclonic eddy at the shelf edge northeast of Taiwan is an important pathway for exchange of dissolved materials between the ECS continental shelf and the Kuroshio. Fortunately, the ocean model faithfully reproduces the countercurrent as well as a cyclonic eddy with which upwelling is generally associated (see Fig. 6b) (Chuang et al., 1993a; Hsueh et al., 1992; Liu et al., 1992; Tang et al., 2000; Wong et al., 2000). However, owing to its small spatial scale $(\sim 70 \mathrm{~km}$ as reported by (Tang et al., 1999)) the cyclonic eddy is not easily identified in Fig. 6a which is exclusively plotted every four grid points to clearly show the main ocean current such as Kuroshio and TWC.

Furthermore, the model agrees quantitatively with observations. The model provides relatively good annual mean water fluxes $21.38 \mathrm{~Sv}$ $\left(1.0 \mathrm{~Sv}=1.0 \times 10^{6} \mathrm{~m}^{3} / \mathrm{s}\right)$ for ET, $1.03 \mathrm{~Sv}$ for TS, and $0.04 \mathrm{~Sv}$ for CR, which agree quantitatively with the measurements $21.45 \mathrm{~Sv}$ across ET
(Johns et al., 2001), 1.20 Sv across TS (Isobe, 2008), and climatological mean 0.03 Sv for Changjiang River (Chu et al., 2009; Piao et al., 2010), respectively. As shown in Fig. 3, both the seasonal cycle and the magnitude of the water fluxes across the Changjiang River (CR), Taiwan Strait (TS), and a section East of Taiwan (ET) are faithfully reproduced, respectively. In addition, the modeled and observed salinities as well as temperature are in very good agreement throughout the water column in summer 2009 (Yang et al., 2011, 2012), suggesting that the model is good enough to investigate the phosphate transport off the coast of Zhejiang.

Next, the modeled daily mean phosphate distributions from Control run are provided in Fig. 7 by comparisons with the observed phosphate distributions during summer cruise in 2009. In Fig. 7, it is immediately clear that the observational phosphate distributions are strikingly reproduced by the daily mean model results from the Control run, although the biochemical processes are not considered in the model. In Fig. 7a and b, it is interesting to note that both the magnitude and the distribution pattern of phosphate measurements are correctly represented by the model results, especially in the bottom water. In Fig. 7c and d, of particular note is that modeled phosphate concentration distribution faithfully reproduced the two observed high phosphate cores. In addition, in Fig. 7c and d, the phosphate contours near the coast also tilt downward as the observed contours do, which indicates the existence of the upwelling. In Fig. 7e, there also is a high phosphate core in the bottom water; the observed phosphate concentration 

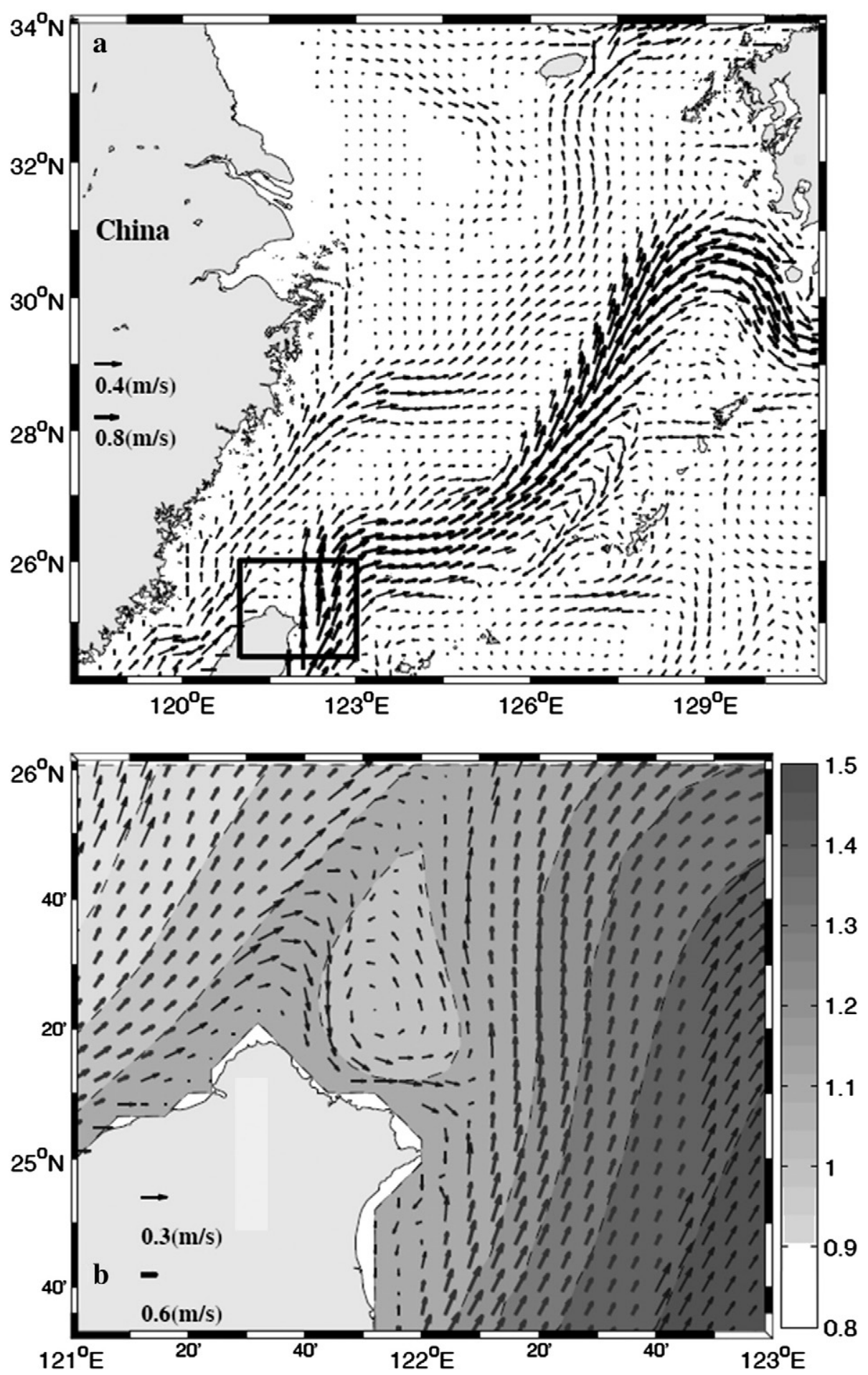

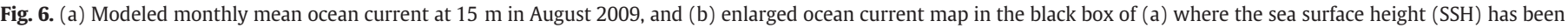
overlapped. The interval of SSH contour is $0.1 \mathrm{~m}$. In (a), ocean current vectors are plotted every four grid points but every one grid point in (b).

in this core is $0.1 \mu \mathrm{mol} \mathrm{dm} \mathrm{dm}^{-3}$ higher than that in the bottom water of Fig. 7a and c. The modeled phosphate concentration is $0.1 \mu \mathrm{mol} \mathrm{dm} \mathrm{m}^{-3}$ less than observations in the bottom water of transect DH3 (see Fig. 7e and f), although the modeled results properly reflect the distribution pattern of observed phosphate. It has been shown in Yang et al. (2011) that the maximum salinity in the bottom water of DH3 transect has the same value ( 34.4) as that in the bottom water of transects DH2 and DH5. Therefore, the phosphate in the bottom water of transect DH3 mainly originates from the bottom water of transects DH2 and DH5, which is subsequently advected northeastward to the transect DH3. Consistent with this view point is the model result as is shown in Fig. $7 \mathrm{~b}, \mathrm{~d}$ and $\mathrm{f}$, where the maximum phosphate concentration remains a constant value of $0.7 \mu \mathrm{mol} \mathrm{dm}{ }^{-3}$. In addition, the modeled phosphate in Fig. 7e tends to be slightly larger than the observed phosphate in the upper layer, although the distribution pattern of modeled phosphate matches that of the observations very well. In fact, in Fig. 7e and $\mathrm{f}$ the phenomenon of modeled larger phosphate concentration in upper layer but smaller in deep water than the observations can be immediately 

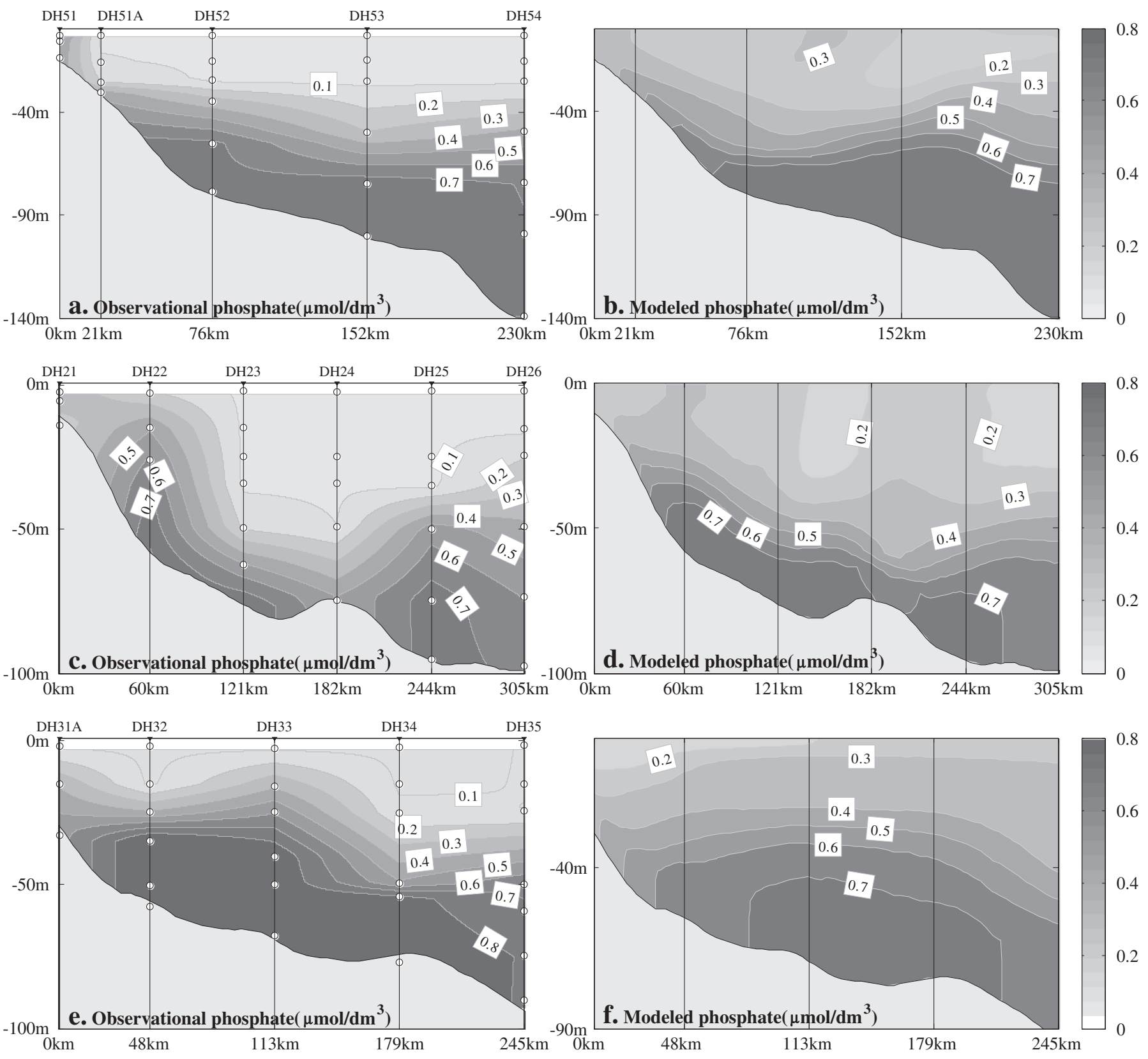

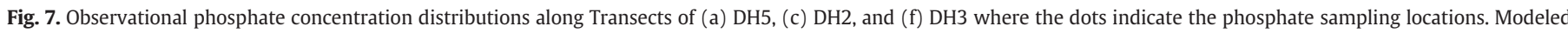

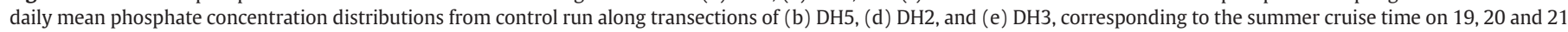
August 2009, respectively.

explained by the alga uptake in the euphotic zone. The algal uptake has twofold functions. The first function is that the higher phosphate concentration relative to the observations in the upper layer will be decreased due to the uptake of the phytoplankton living in the euphotic zone. At the same time, the continuous sinking of biogenic particles due to the death of phytoplankton in the surface water supplies the bottom water with phosphate by the remineralization of biogenic particles due to microbial degradation of biogenic particles in the deep water (Fang, 2004). Therefore, the phosphate cascade from the surface water to the bottom water by the biochemical processes, plays an important role in adjusting the phosphate distribution along the transect DH3, where the algal bloom is more frequently reported relative to the other transects DH5 and DH2 in summer (Wang and Wu, 2009). As was reported by Zhang et al. (2007), in the coastal area off Changjiang Estuary, the estimated phosphate flux at the sediment-water interface ranged from 0.006 to $0.078 \mathrm{mmol} \mathrm{m}^{-2} \mathrm{~d}^{-1}$.

Therefore, the difference between observation and model results in the surface and bottom water may result from the biochemical processes. In addition, the model probably shows the correct background phosphate concentration, where the only one factor to drive the phosphate transports is the hydrodynamic processes. Except for the numerical simulation, it is almost impossible to solely distinguish the influence of hydrodynamic processes on phosphate concentration from the field observations. Obviously, the numerical model gives us one kind of methods which enables us to closely investigate the key dynamical processes which controls the phosphate distribution. A particularly encouraging fact is that our model is capable of successfully reproducing the observed phosphate distribution, although 
there is small difference between observation and model results. Thus, the model is further utilized below to conduct process-oriented simulations to investigate the origins of the phosphate off the coast of Zhejiang and to understand the underlying mechanism which drives the phosphate transport.

\section{Discussion}

The objective of this study is to identify the key processes that create the observed high phosphate concentrations off the coast of Zhejiang, and to elucidate which process is dominant. Of particular interest here is the dynamics underlying the phosphate distribution. Therefore, three distinct phosphate sources (Changjiang River, Taiwan Strait and Kuroshio) are first examined. In turn, not only the phosphate transport flux but also the dynamics is discussed in the following sections.

\subsection{Phosphate inputs from Changjiang River, Taiwan Strait and Kuroshio}

Case 1, 2 and 3 experiments have been carefully carried out to closely examine the distinctive phosphate input from Changjiang River, Taiwan Strait and Kuroshio, respectively.

Fig. 8a and b shows the modeled daily mean phosphate distribution from Case 1 on the 20 August 2009, corresponding to the survey time of transect DH3. In Fig. 8a and b, it is immediately clear that the phosphate from Changjiang River mainly extends northeastward and generally reaches as far as the Cheju Island, because the Changjiang diluted water mainly extends northeastward in summer due to the northeastward monsoon, as was reported in Beardsley et al. (1985) and Ichikawa and Beardsley (2002). In addition, the southeastward convex contour of phosphate concentration in Fig. 8a is mainly attributed to the abrupt shift of the wind stress on 18 August 2009 (see Fig. 8c and d). An immediate conclusion that can be extracted from the phosphate distribution in Fig. $8 \mathrm{a}$ and $\mathrm{b}$ is that the Changjiang River plays a negligible role in the phosphate distribution of transect DH3, especially in the phosphate distribution of transects DH2 and DH5 in summer. Therefore, Cases 2 and 3 have been run to further examine the key phosphate sources which would effectively control the phosphate distribution off the coast of Zhejiang.

Modeled daily mean phosphate distributions from Case 2 on 20 August 2009, are shown in Fig. 9a, c and e. It is interesting to note that the phosphate from Taiwan Strait can only be found in the upper layer above the depth of $\sim 60 \mathrm{~m}$. In contrast, in the bottom water the modeled phosphate concentration is negligible compared with the observed high phosphate concentration in Fig. 7a, c and e. In fact, the water of Taiwan Strait, with high temperature and low salinity in summer, rushes out of the TS, forming the TWC (see Fig. 1), and then flows northeastward only in the upper layer above the depth of $\sim 60 \mathrm{~m}$ in southern ECS (Guan and Fang, 2006; Hu et al., 2010). Therefore, in Case 2 the phosphate concentration originated from the Taiwan Strait is mainly limited to the upper layer above $\sim 60 \mathrm{~m}$. At the same time, there are two high phosphate concentration cores in Fig. 9c which are directly attributed to the nearshore branch and the offshore branch of TWC (Su et al., 1994). In addition, the
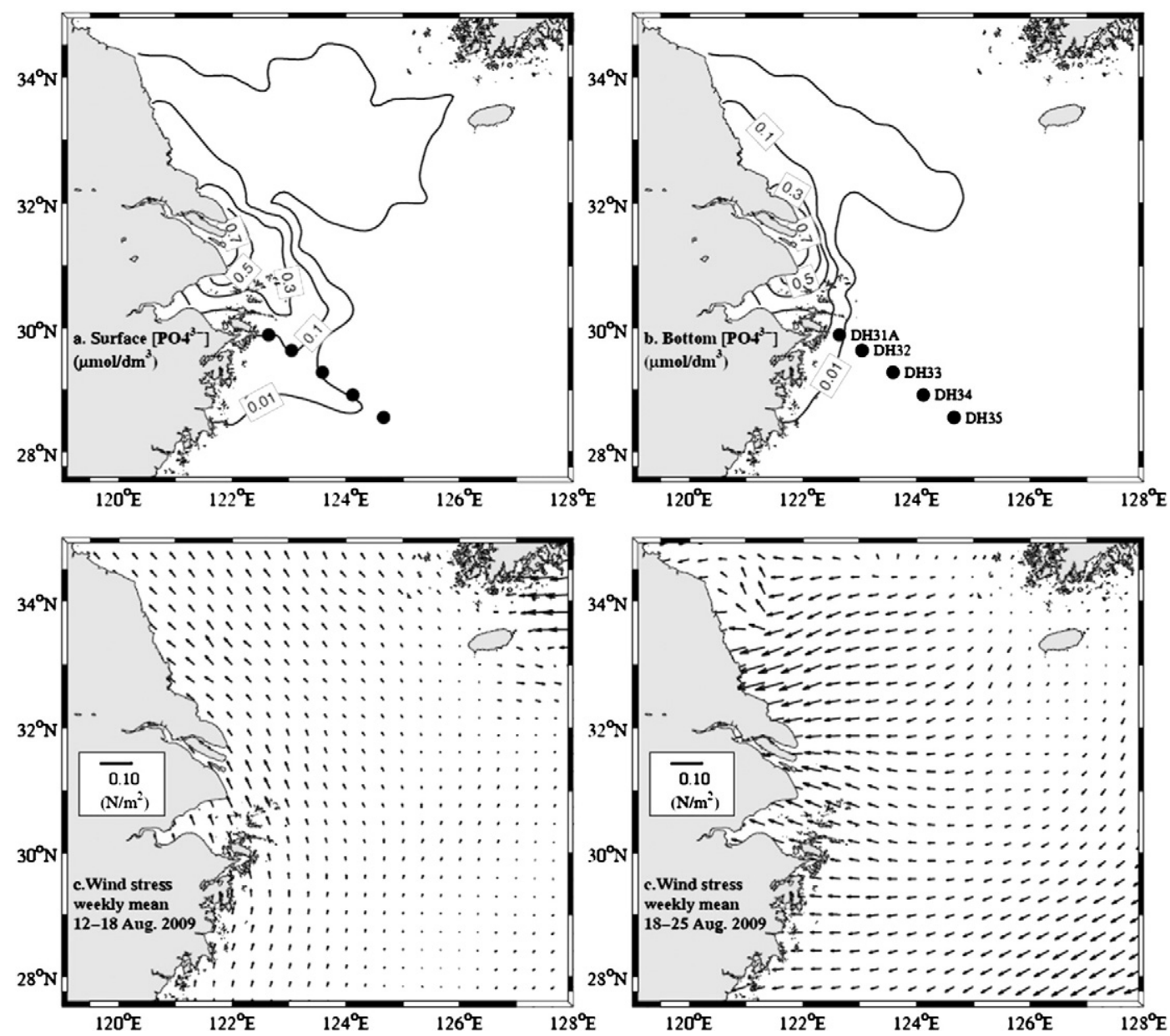

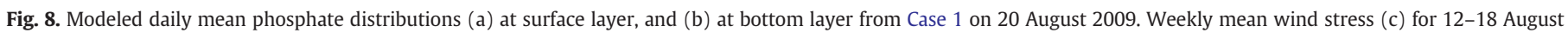
2009, and (d) for 18-25 August 2009. 

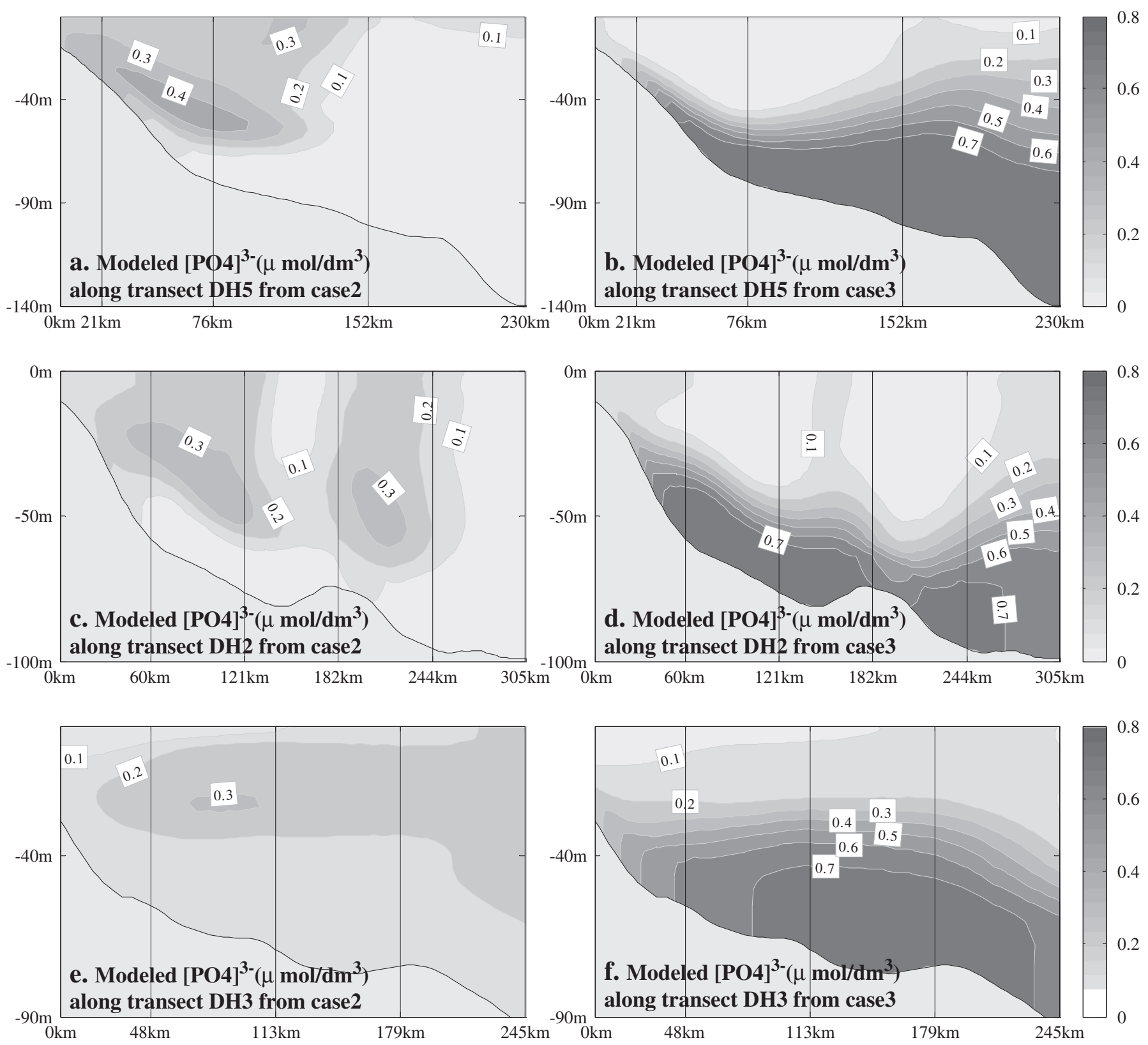

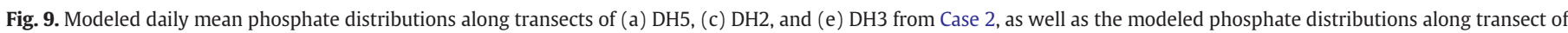
(b) DH5, (d) DH2, and (e) DH3 from Case 3 on 20 August 2009.

small phosphate concentration below the depth of $60 \mathrm{~m}$ can also be attributed to the buoyance blocking caused by the big density difference between the light water from Taiwan Strait in the upper layer and the dense water in the bottom layer. Moreover, the low phosphate concentration in the bottom water properly implies that the bottom water and the upper layer water have different origins.

As shown in Fig. 9b, $d$ and $f$, the phosphate distribution from Case 3 immediately confirmed that the bottom water in Fig. 9a, c and e has distinctively different phosphate origin relative to the upper layer water. To our surprise, Fig. 9b, d and f shows more consistency with the observed phosphate distribution than that from the Control run, because the higher phosphate concentration in surface water relative to the measurements in Control run has been decreased in Case 3 while excellent agreement between observed and modeled results remains in the bottom water. In light of the comparison between Figs. 7 and 9, it should come as no surprise that off the coast of Zhejiang the observed phosphate distribution is mainly controlled by the phosphate input from the east of Taiwan, although the phosphate input from Taiwan Strait also plays an important role in the upper layer. However, another question immediately arises: where do they exactly originate, and how much water and phosphate can be transported to the area off the coast of Zhejiang?

\subsection{Origin of phosphate off the coast of Zhejiang and their contributions}

As reported in Gong et al. (2003) and Wong et al. (1998), the rate of primary production in ECS was regulated by the availability of the nutrients, especially the phosphate from summer to autumn. At the same time, the Kuroshio subsurface water northeast of Taiwan is enriched in phosphate with a low N/P ratio of 10 (Chen et al., 2004; Zhang et al., 2007). However, off the coast of Zhejiang the phosphate in the surface water is absent relative to the nitrate, especially in the Changjiang River plume with a N/P ratio as high as 38.2 in August 2003 (Chen et al., 2004, 2006; Gong et al., 1996). Therefore, it is very important to identify the sensitive area northeast of Taiwan which would effectively influence the phosphate distribution off the coast of 
Zhejiang. In order to identify the sensitive area, we conducted two additional experiments: Case 3a and b. In Case 3a, the phosphate distribution along the section PRS3 (see Fig. 2) is same to that of Case 3 (see Fig. 5), but to the west of $122.4^{\circ} \mathrm{E}$ the phosphate concentration between $\sim 100 \mathrm{~m}$ and $\sim 300 \mathrm{~m}$ (see the Origin Area in Fig. 10a) is set to zero. In contrast, in Case 3b only the observed phosphate concentration in the Origin Area remains the same to that of Case 3 (see Fig. 5), while the phosphate concentration out of the Origin Area is set to zero (see Fig. 11a).

On the basis of a larger number of experiments, it is found that only the phosphate in the Origin Area (see Fig. 10a) affects the phosphate distribution off the coast of Zhejiang. As shown in Fig. 10b, c and d, the phosphate distribution along transects DH5, DH3 and DH2 almost disappears when the phosphate concentration in the Origin Area is set to zero. In other words, the phosphate input from the Origin Area (see Fig. 10) becomes critical to maintaining the correct phosphate distribution in the water column off the coast of Zhejiang. Even so, one question still arises: how does the phosphate in the Origin Area northeast of Taiwan influence the phosphate distribution in the euphotic zone off the coast of Zhejiang where algal blooms are frequently observed (Wang and $\mathrm{Wu}, 2009)$ ?

In order to answer this question, Case $3 \mathrm{~b}$ has been done to show the phosphate distribution which is solely influenced by the phosphate input from the Origin Area (see Fig. 11a). The modeled results from Case $3 \mathrm{~b}$ (see Fig. 11b) clearly illustrate the phosphate distribution in the surface water. Of particular interest here is that just off the coast of Zhejiang, there is a distinctively high phosphate tongue with a maximum of phosphate near the coast. Obviously, the high phosphate concentration is absolutely caused by the Kuroshio subsurface water northeast of Taiwan, because in Case 3b the only one phosphate input comes from the Origin Area northeast of Taiwan (see Fig. 11a) while both the phosphate input from Changjiang River and that from Taiwan Strait are set to zero during the simulation of Case 3b. To our surprise, off the coast of Zhejiang the weekly mean chlorophyll distribution from the Moderate Resolution Imaging Spectroradiometer (MODIS) onboard of Aqua Satellite (Wang et al., 2004) during 17-24 August 2009 (see Fig. 11c), also shows a strikingly high chlorophyll tongue which is frequently observed in summer (He et al., 2010). The modeled high phosphate tongue shows a good agreement with the high chlorophyll tongue. In other words, the area of high phosphate concentration is nearly coincident with the area of the high chlorophyll. Obviously, the high chlorophyll west of Box2 is readily attributed to the discharge of Changjiang River which is not included during the simulation of Case 3b. In fact, such a good agreement between chlorophyll and the modeled phosphate distribution off the coast of Zhejiang can be easily understood according to the previous studies that the rate of primary production in ECS is mostly regulated by the availability of phosphate (Chen et al., 2004, 2006; Gong et al., 1996, 2003; Wong et al., 1998). Furthermore, the good agreement probably implies that the chlorophyll distribution off the coast of Zhejiang is remotely controlled by the phosphate from the Origin Area northeast of Taiwan rather than by the phosphate from either the neighboring Changjiang River or the Taiwan Strait. Therefore, the phosphate budget has been done in order to quantitatively examine the phosphate input from Changjiang River, Taiwan Strait and Origin Area northeast of Taiwan, respectively.

First, the modeled daily mean phosphate flux from Changjiang River, Taiwan Strait and Origin Area northeast of Taiwan has been carefully calculated from 1 June through 1 September 2009, as are shown in Fig. 12a and b. Interesting to note is that the phosphate flux either from the Origin Area or from the Taiwan Strait is an order of magnitude larger than that from the Changjiang River due to its small water flux of $\sim 0.04 \mathrm{~Sv}$ (see Fig. 3). At the same time, the phosphate flux from the Origin Area is almost three times larger than that from the Taiwan Strait. At this point, it appears to be reasonable that the Kuroshio subsurface water contributes $\sim 70 \%$ of externally sourced phosphate (Chen, 2008 ) in the ECS. In addition, in order to get the total phosphate amount, the phosphate flux from Changjiang River, Taiwan Strait and Origin Area has been integrated from 1 June to 1 September 2009, respectively. As is shown in Table 2, the modeled total phosphate amount agrees quantitatively with the previous results such as the total phosphate input from Origin Area $\left(4.9 \times 10^{9} \mathrm{~mol}\right)$ which matches the sum $\left(4.83 \times 10^{9} \mathrm{~mol}\right)$ of the phosphate from Kuroshio tropical water $\left(1.67 \times 10^{9} \mathrm{~mol}\right)$ and Kuroshio intermediate water $\left(3.16 \times 10^{9} \mathrm{~mol}\right)$ (Chen and Wang, 1999). For comparison, the mean phosphate fluxes from Changjiang River, Taiwan Strait and Origin Area northeast of Taiwan (see Table 3) have also been calculated, respectively. Of particular interest here is that for the phosphate flux from the Origin Area our model shows an exactly same value of $0.68 \mathrm{kmol} / \mathrm{s}$ as that from the Kuroshio subsurface water in Liu et al. (2000). In a word, the modeled phosphate inputs agree well with the previous studies (Chen and Wang, 1999; Chung et al., 2001; Liu et al., 2000), although the calculation of phosphate fluxes (see Tables 2 and 3 ) is based on different methods. For example, in Liu et al. (2000) the constant water flux (1.88 Sv) from Taiwan Strait as well as a constant phosphate concentration $\left(0.13 \mu \mathrm{mol} \mathrm{dm}{ }^{-3}\right)$ has been directly used to get the phosphate flux across the Taiwan Strait $\left(1.88 \mathrm{~Sv} \times 0.13 \mu \mathrm{mol} \mathrm{dm}{ }^{-3} \approx 0.25 \times 10^{3} \mathrm{~mol} \mathrm{~s}^{-1}\right)$. In addition, our study illustrates somewhat less phosphate flux from Taiwan Strait than previous studies (see Tables 2 and 3). As shown in Chen (2003), the flux reported in Chung et al. (2001) and Liu et al. (2000) should have been much lower, because their work was based on a rare event. On the basis of the comparisons above, it is immediately clear that our model is strong enough to capture both the variability of water flux and the magnitude of phosphate input. Next, the phosphate budget is closely examined in the area off the coast of Zhejiang where algal bloom is frequently observed (Wang and Wu, 2009).

Then, two typical high chlorophyll domains off the coast of Zhejiang (see Box1 and Box2 in Fig. 11b and c) are particularly selected to examine the phosphate influence from different origins. In turn we computed the daily mean phosphate inventory in Box1 and Box2, corresponding to Cases 1, 2 and 3b, respectively. Fig. 12c and d shows the daily mean phosphate amount in Box1 and Box2, respectively. As for the phosphate contribution to the Box1, the Taiwan Strait, however, seems to play an equivalently important role as the Origin Area, though the phosphate amount from Origin Area shows somewhat larger than that from Taiwan Strait. Instead, the phosphate amount from Origin Area shows somewhat less than that from Taiwan Strait in Box2 where an upwelling is frequently reported (Lv et al., 2006; Zhao et al., 2001). In summer, the phosphate from Changjiang River mainly extends northeastward as shown in Fig. 8 and its phosphate contribution to either Box1 (with a maximum $0.01 \times 10^{9} \mathrm{~mol}$ ) or Box 2 (with a maximum $0.03 \times$ $10^{9} \mathrm{~mol}$ ) appears to be negligible compared to that from Origin Area and Taiwan Strait. In contrast, the phosphate from Taiwan Strait seems to contribute a lot of phosphate to the area off the coast of Zhejiang. However, the phosphate will be consumed by the phytoplankton in the upper layer during the long period (about three weeks, see Fig. 11c and d) of the phosphate transport from Taiwan Strait to the area off the coast of Zhejiang. Then, the phosphate concentration stemmed from Taiwan Strait may be accordingly decreased when they reaches the area off the coast of Zhejiang. In contrast, the huge phosphate from the Origin Area northeast of Taiwan is almost transported, as conservative variable, to the area off the coast of Zhejiang, because the phosphate transport is mostly performed in the deep water which prevents it from the biological consumption in the euphotic zone. Furthermore, the phosphate concentration may be properly increased due to the remineralization of biogenic particles owing to the microbial degradation of biogenic particles in the deep water. For this reason, off the coast of Zhejiang the phosphate contribution from the Origin Area can be accordingly increased but that from the Taiwan Strait will be decreased. A question still remains unclear: why can the phosphate in the Origin Area northeast of Taiwan only be found in surface water off the coast of Zhejiang (see Fig. 11b) rather than other places in summer? 

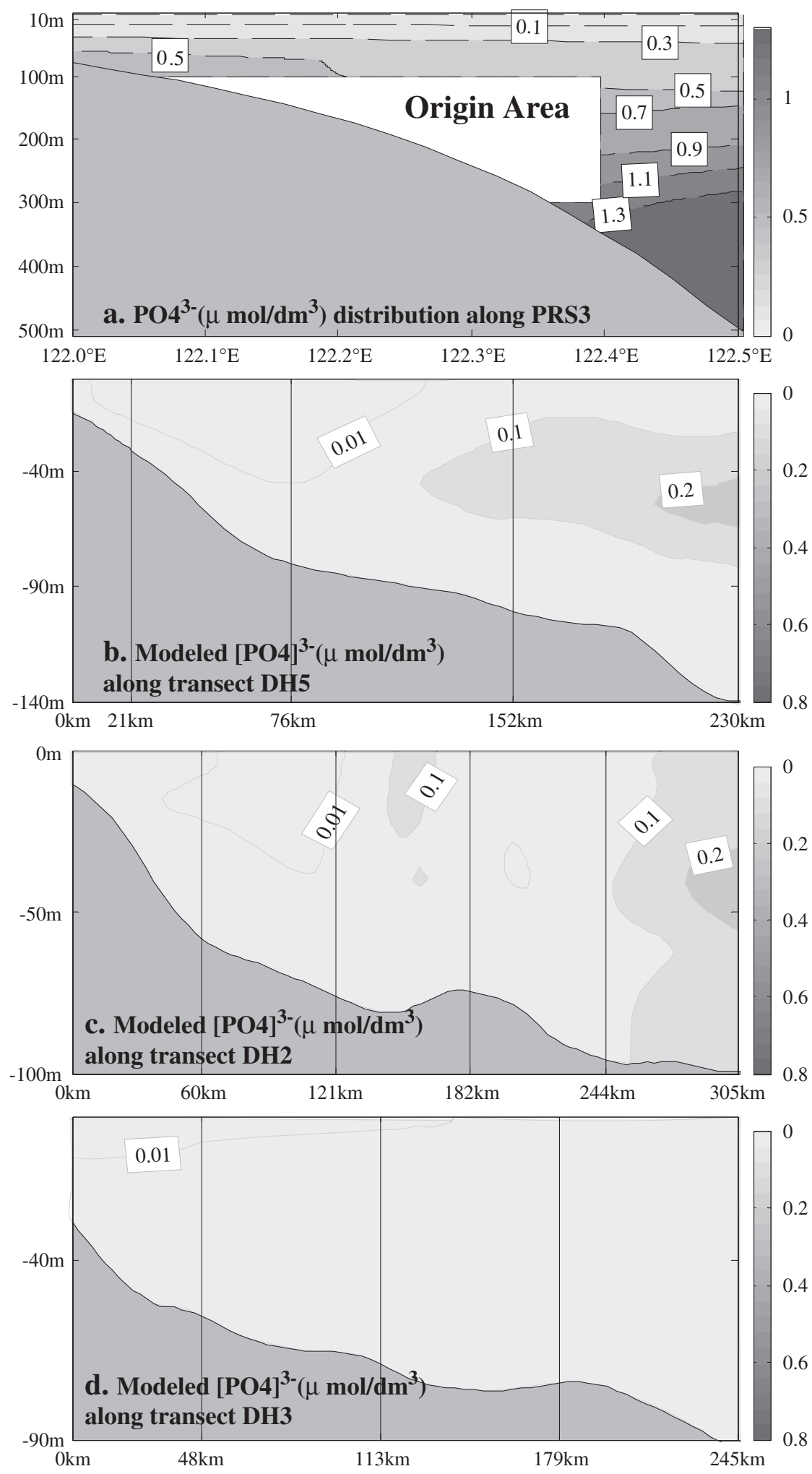

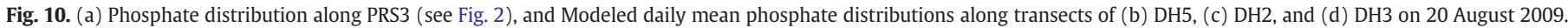

\subsection{Dynamics underlying the phosphate transport}

As is reported in Yang et al. (2011, 2012), the NKBC (see Fig. 1) closely links Kuroshio northeast of Taiwan to the area off the coast of Zhejiang. Therefore, the NKBC probably plays an important role in forming the distinctively high phosphate distribution off the coast of Zhejiang.
At first, the water flux of NKBC is estimated. Fig. 13 shows monthly mean volume flux along a line A-B-C-D on August 2009. It is immediately clear that the KBC (see Fig. 1) enters the ECS between A and B, and then quickly rejoins the mainstream of Kuroshio between $B$ and $C$ (see the middle panel of Fig. 13). At the same time, in the deep water (water depth $>65 \mathrm{~m}$ ), there is a large onshore flux of $1.85 \mathrm{~Sv}$ between A and B (see the middle panel of Fig. 13); part of the onshore water 

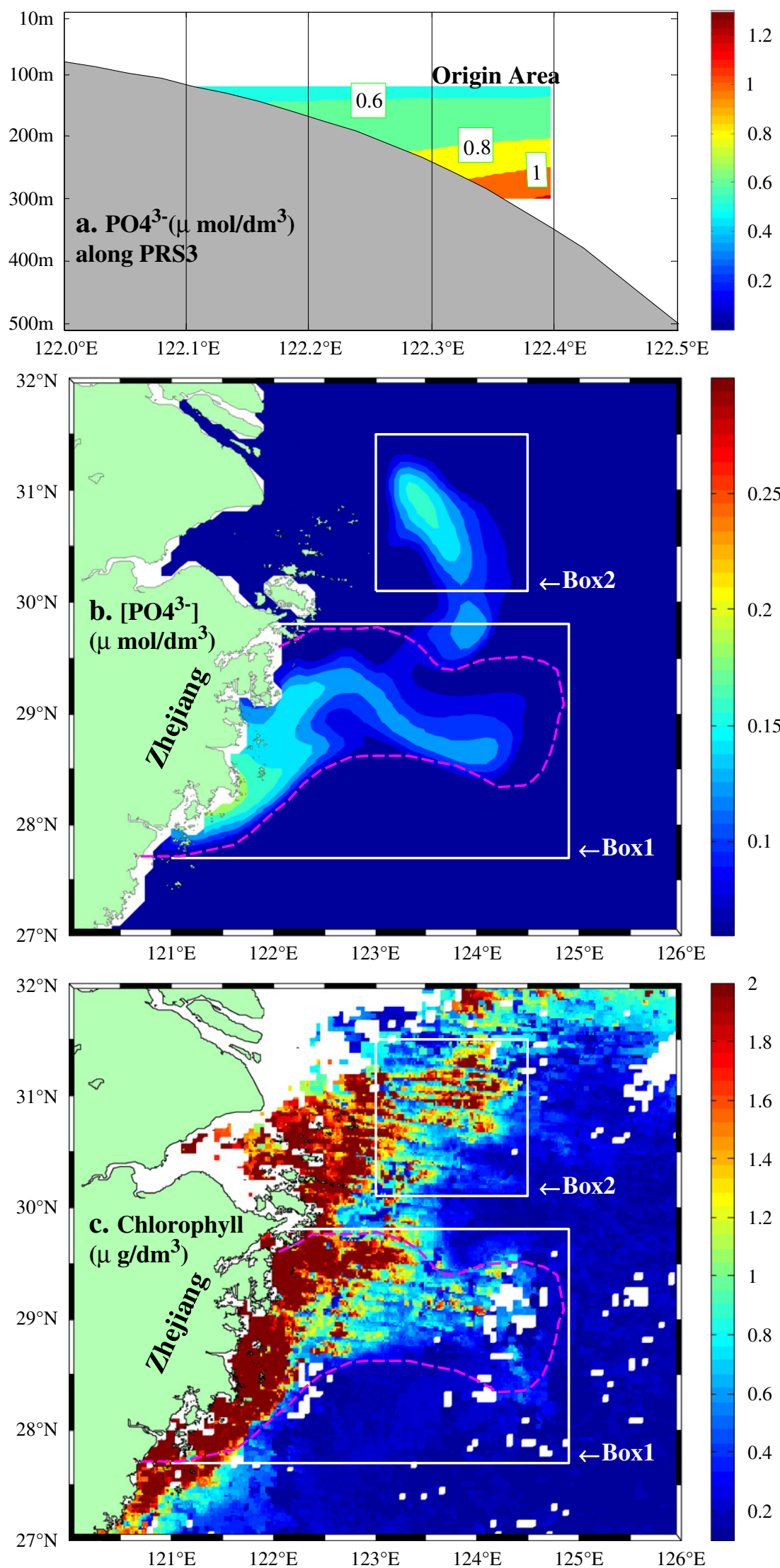

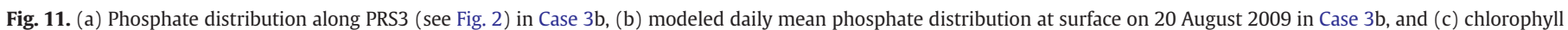
distribution at the surface from weekly mean satellite data during 17-24 August 2009. 

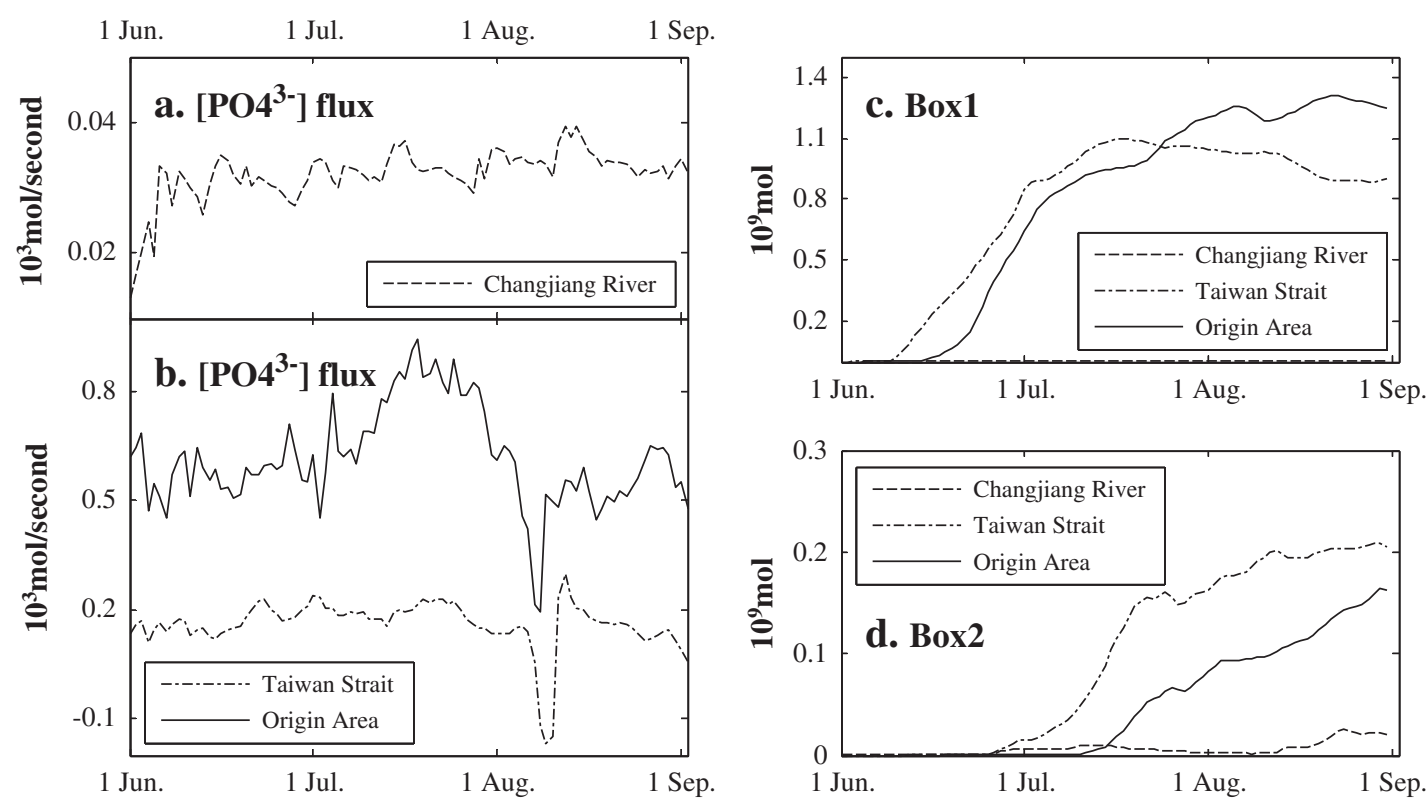

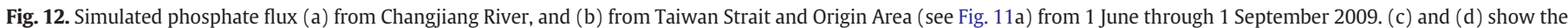
total phosphate amount in Box1 and Box2 (see Fig. 11) from 1 June through 1 September 2009, respectively.

$(0.80 \mathrm{~Sv})$ exits the ECS between B and C in the deep water (water depth $>65 \mathrm{~m}$ ), while another part $(0.74 \mathrm{~Sv})$ exits the ECS between $\mathrm{C}$ and $\mathrm{D}$ in the deep water (water depth $>50 \mathrm{~m}$ ). Obviously, in the deep water there is an unbalanced onshore volume flux of $0.31 \mathrm{~Sv}$ (1.85 $0.80-0.74=0.31 \mathrm{~Sv}$, see the middle panel of Fig. 13). On the other hand, there is a total onshore flux of $0.34 \mathrm{~Sv}(4.42-2.83-1.25=$ $0.34 \mathrm{~Sv}$, see the bottom panel of Fig. 13). Therefore, the onshore flux across the transect A-B-C-D mainly depends on the onshore intrusion of the deep water. In fact, the deep onshore flux ( 0.3 Sv) is chiefly controlled by the NKBC, as is reported by Yang et al. (2012). In other words, the volume flux of NKBC is $\sim 0.3 \mathrm{~Sv}$, which is almost 10 times larger than the discharge of Changjiang River. According to the huge water flux of NKBC as well as the corresponding high phosphate concentration $\left(\sim 1 \mu \mathrm{mol} \mathrm{dm}{ }^{-3}\right)$ in the Origin Area which also is the origin of NKBC (Yang et al., 2011, 2012), the high phosphate concentration and the high chlorophyll in the surface water off the coast of Zhejiang is likely attributed to the combination of the NKBC and TWC.

In order to clarify the question, Fig. 14 shows monthly mean current at the bottom layer as well as the ocean current at the depth of $10 \mathrm{~m}$ on August 2009. In the bottom water, the NKBC is markedly demonstrated by the green arrows (see Fig. 14a), which clearly indicates the crossshelf transport of the phosphate from the Kuroshio northeast of Taiwan to the area off the coast of Zhejiang. In Fig. 14b where the surface ocean

Table 2

Phosphate input from Changjiang, Taiwan Strait and Kuroshio in summer 2009.

\begin{tabular}{|c|c|c|c|}
\hline Input source & $\begin{array}{l}\mathrm{PO}_{4} \\
\left(10^{9} \mathrm{~mol}\right)\end{array}$ & Period of calculation & References \\
\hline Changjiang & 0.3 & From 1 Jun. to 1 Sept. & This work \\
\hline Taiwan Strait & 1.3 & From 1 Jun. to 1 Sept. & This work \\
\hline Kuroshio $^{a}$ & 4.9 & From 1 Jun. to 1 Sept. & This work \\
\hline $\begin{array}{l}\text { Kuroshio surface } \\
\text { water }\end{array}$ & 0.11 & Summer & Chen and Wang (1999) \\
\hline $\begin{array}{l}\text { Kuroshio tropical } \\
\text { water }\end{array}$ & 1.67 & Summer & Chen and Wang (1999) \\
\hline $\begin{array}{l}\text { Kuroshio } \\
\text { intermediate } \\
\text { water }\end{array}$ & 3.16 & Summer & Chen and Wang (1999) \\
\hline Taiwan Strait & 1.6 & Summer & Chen and Wang (1999) \\
\hline
\end{tabular}

a The phosphate from Kuroshio means the phosphate input from the Origin Area (see Fig. 11a). current in the box of Fig. 14a are specially enlarged, of particular interest is the low sea surface height (SSH) immediately off the coast of Zhejiang. It should come as no surprise that the low SSH as well as the corresponding upwelling is mainly caused by the abrupt change of the direction of TWC which flows almost parallel to the coast of China until it reaches $28.5^{\circ} \mathrm{N}$ where it abruptly turns to east (see the big white arrows in Fig. 14b). Thus, off the coast of Zhejiang the bottom water must upwell into the surface layer to compensate the water mass loss due to the offshore water transport that resulted from the eastward flowing TWC. In addition, the southward flowing Changjiang diluted water (CDW, see the big gray arrows in Fig. 14b) also benefits from the low SSH off the coast of Zhejiang. Then, a positive vorticity is generated off the coast of Zhejiang, where a large velocity shear is formed by the southward CDW and northeastward TWC (see Fig. 14b). Thus, the upwelling just off the coast of Zhejiang is further strengthened by the positive vorticity.

So far, the observed high phosphate as well as the high chlorophyll tongue can be satisfactorily explained by the NKBC and intensified upwelling. Although there are biochemical reasons to expect differences between the model and observations, until uniquely biochemical processes are observed and quantified, the proposed mechanism remain appropriate. This mechanism shows us an example that the algal bloom off the coast of China may not only be influenced by the local nutrient input (such as river runoff) but also is subject to the control of the deep sea water in the open sea. This mechanism could well apply in other coastal water in the world.

Table 3

Phosphate input flux from Changjiang, Taiwan Strait and Kuroshio in summer 2009.

\begin{tabular}{llll}
\hline Input source & $\mathrm{PO}_{4}(\mathrm{kmol} / \mathrm{s})$ & Period of calculation & References \\
\hline Changjiang & 0.04 & From 1 Jun. to 1 Sept. & This work \\
$\begin{array}{l}\text { Taiwan Strait } \\
\text { Kuroshio }\end{array}$ & 0.18 & From 1 Jun. to 1 Sept. & This work \\
$\begin{array}{l}\text { Kuroshio subsurface } \\
\quad 0.68\end{array}$ & 0.68 & From 1 Jun. to 1 Sept. & This work \\
$\quad$ water & & Summer & Liu et al. (2000) \\
$\begin{array}{l}\text { Taiwan Strait } \\
\text { Taiwan Strait }\end{array}$ & 0.25 & Summer & Liu et al. (2000) \\
\hline
\end{tabular}

b The phosphate from Kuroshio means the phosphate input from the Origin Area (see Fig. 11a). 

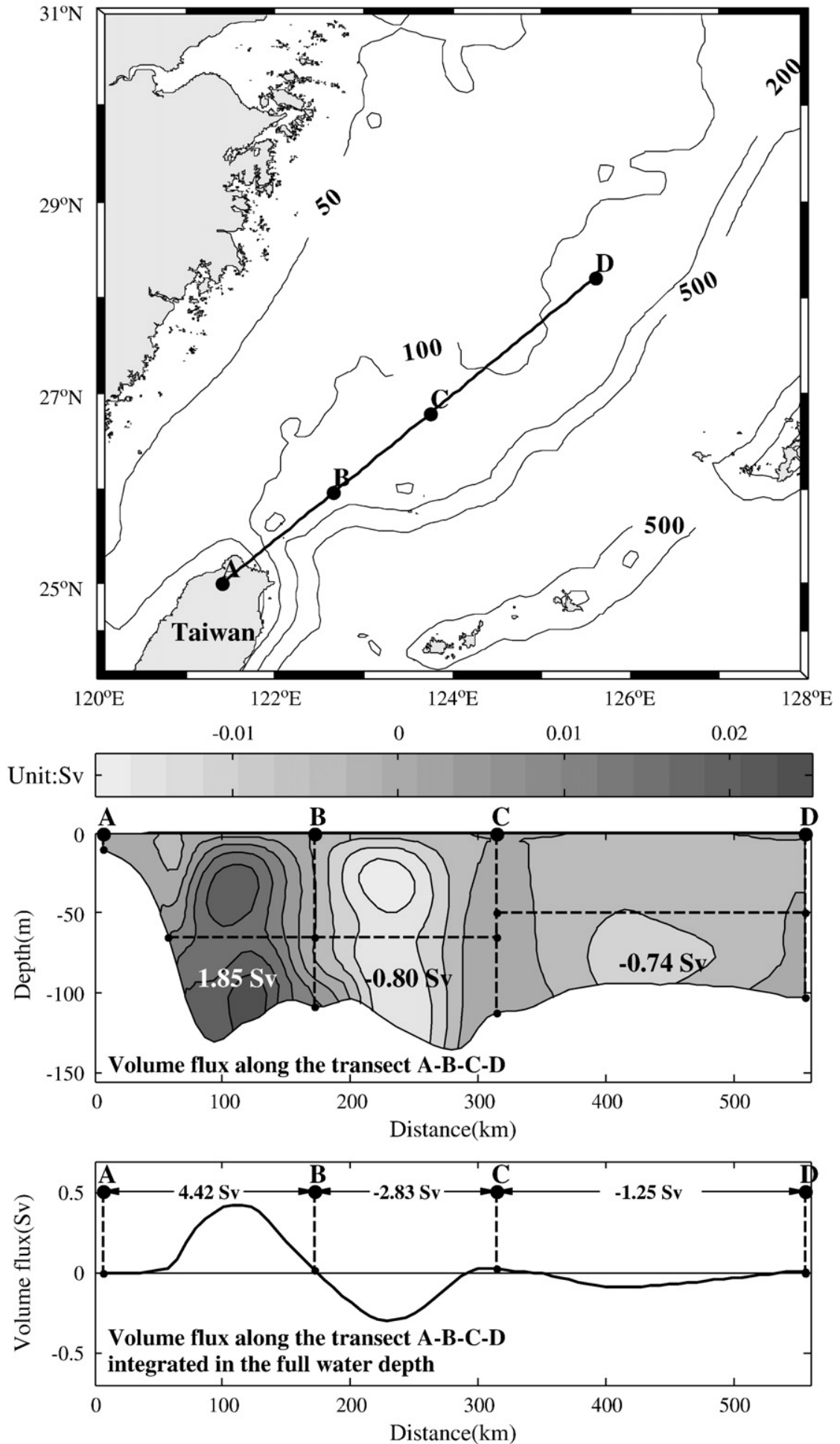

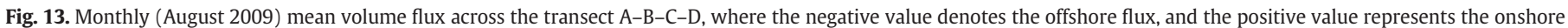

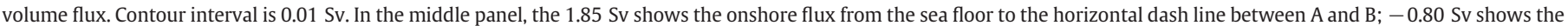
offshore flux from the sea floor to the horizontal dash line between B and C; -0.74 Sv shows the offshore flux from the sea floor to the horizontal dash line between C and D.

\section{Conclusion}

Off the coast of Zhejiang, the observed high phosphate distribution is faithfully reproduced by our model. On the basis of numerical experiments, the dominant phosphate origin (see the Origin Area in Fig. 15) has been identified. Furthermore, a forcing mechanism has been proposed to explain the observed high phosphate distribution in the bottom water as well as the observed high chlorophyll tongue in the surface water off the coast of Zhejiang. The forcing mechanism can be schematically demonstrated by Fig. 15. In the bottom water on the ECS shelf, the huge phosphate in the Origin area northeast of Taiwan has been continuously transported to the bottom water off the coast of Zhejiang by the NKBC ( 0.3 Sv) which only exists in the deep water, while the TWC mainly flows in the upper $60 \mathrm{~m}$. On the other hand, off 

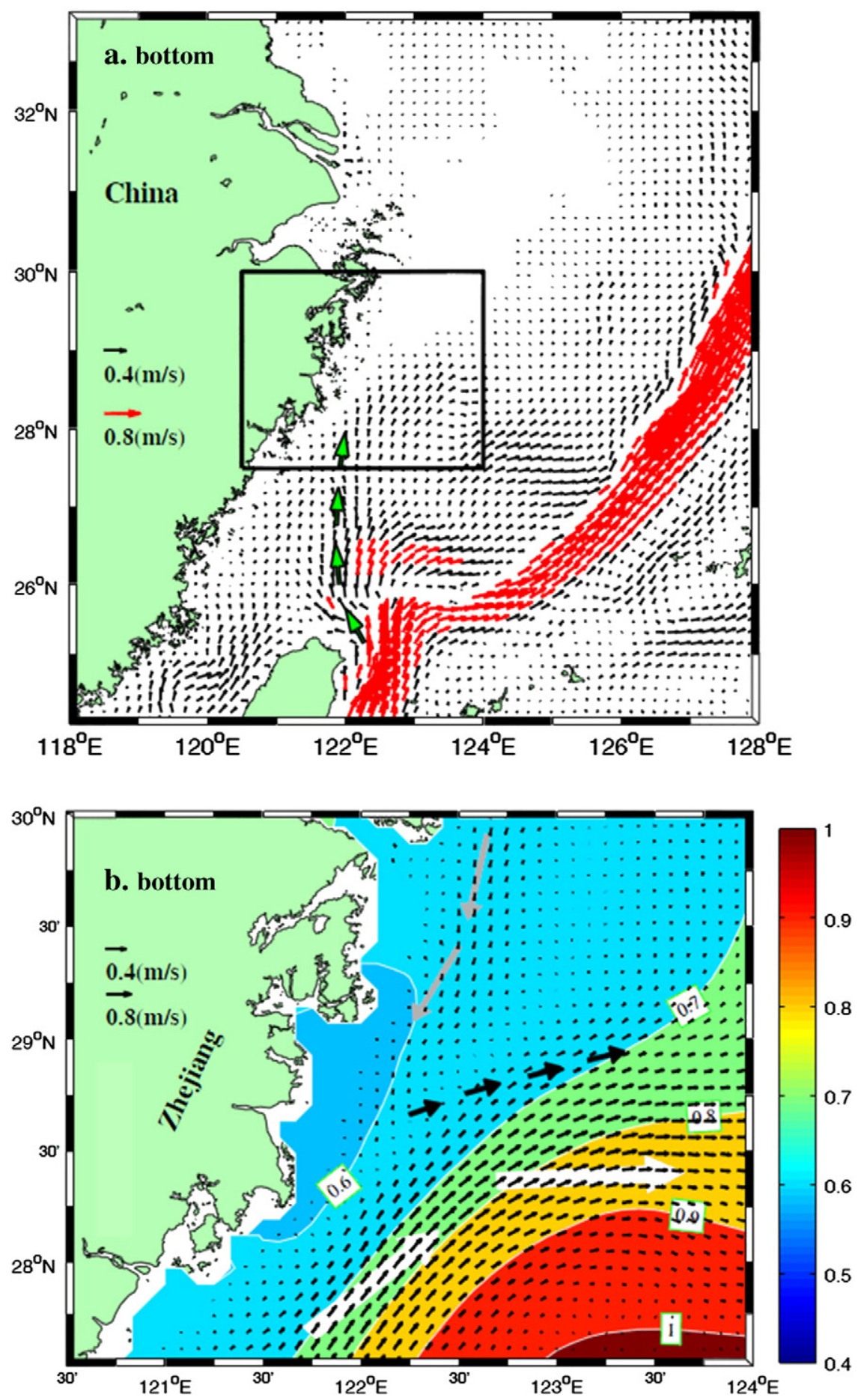

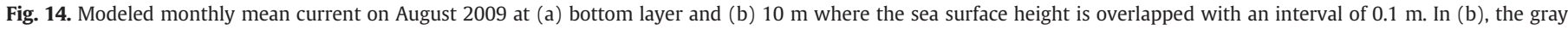

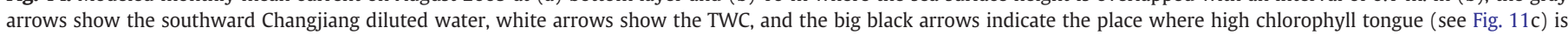
frequently observed. In (a), the bottom current is replaced by the current at $200 \mathrm{~m}$ when the water depth is deeper than $200 \mathrm{~m}$.

the coast of Zhejiang the upwelling closely linked the phosphate-rich bottom water to the oligotrophic surface water. In turn, the upwelled phosphate-rich bottom water is further transported offshore by the northeastward flowing TWC off the coast of Zhejiang. The high phosphate tongue is first formed off the coast of Zhejiang, and later the high chlorophyll tongue formed because the growth of phytoplankton is regulated by the availability of the phosphate. Therefore, off the coast of Zhejiang the NKBC plays a crucial role in balancing the surface phosphate consumption due to biological processes above, and in maintaining the high chlorophyll there which is sometimes influenced by the occasional flood of the Changjiang River (Gong et al., 2011). Furthermore, the frequently observed abnormal large algal bloom off the coast of Zhejiang is probably attributed to the variation of the NKBC and to the upwelling.

\section{Acknowledgments}

This paper was supported by the Innovation Project of Chinese Academy of Sciences (KZCX2-EW-209), National Basic Research Program of China (2012CB956000), 973 Project (2009CB421205), Chinese 


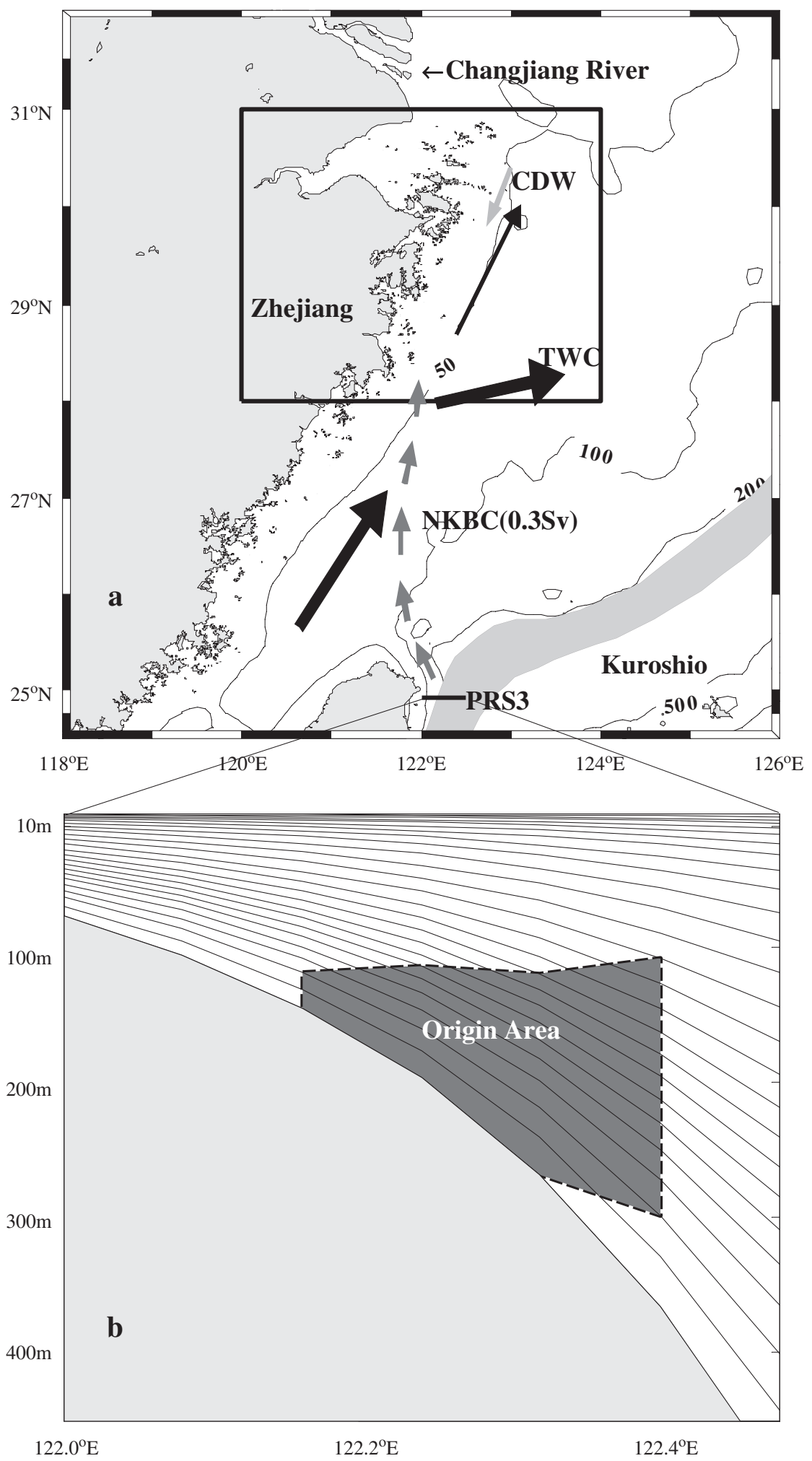

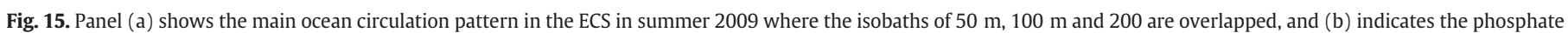
origin of the water off the coast of Zhejiang.

Academy of Sciences Strategy Program (XDA10020104, XDA10020305), Global Change and Air-Sea Interaction, National Natural Science Foundation of China through Grant 40976008, and '100 talent programme of Chinese Academy of Sciences' (KZCX2-YW-215-3). This paper was also supported by High Performance Computing Center, Institute of Oceanology, Chinese Academy of Sciences in Qingdao as well as
National Supercomputer Center in Jinan. The satellite data was provided by the satellite data receiving station of the Sate Key Laboratory of Satellite Ocean Environment Dynamics, Second Institute of Oceanography of State Oceanic Administration, China. We especially appreciate the Ocean Carbon Group from Xiamen University for providing the phosphate data. 


\section{References}

Beardsley, R.C., Limeburner, R., Yu, H., Cannon, G.A., 1985. Discharge of the Changjiang (Yangtze River) into the East China Sea. Cont. Shelf Res. 4, 57-76.

Chen, C.T.A., 1996. The Kuroshio intermediate water is the major source of nutrients on the East China Sea continental shelf. Oceanol. Acta 19, 523-527.

Chen, C.T.A., 2003. Rare northward flow in the Taiwan Strait in winter: a note. Cont. Shelf Res. 23 (3-4), 387-391. http://dx.doi.org/10.1016/S0278-4343(02)00209-1.

Chen, C.T.A., 2008. Distributions of nutrients in the East China Sea and the South China Sea connection. J. Oceanogr. 64, 737-751.

Chen, C.T.A., 2009. Chemical and physical fronts in the Bohai, Yellow and East China seas. J. Mar. Syst. 78, 394-410.

Chen, C.T.A., Wang, S.L., 1999. Carbon, alkalinity and nutrient budgets on the East China Sea continental shelf. J. Geophys. Res. Oceans 104, 20675-20686.

Chen, C.T.A., Ruo, R., Pai, S.C., Liu, C.T., Wong, G.T.F., 1995. Exchange of water masses between the East-China-Sea and the Kuroshio off Northeastern Taiwan. Cont. Shelf Res. 15, 19-39.

Chen, Y.L.L., Chen, H.Y., Gong, G.C., Lin, Y.H., Jan, S., Takahashi, M., 2004. Phytoplankton production during a summer coastal upwelling in the East China Sea. Cont. Shelf Res. 24, 1321-1338.

Chen, C.C., Chiang, K.P., Gong, G.C., Shiah, F.K., Tseng, C.M., Liu, K.K., 2006. Importance of planktonic community respiration on the carbon balance of the East China Sea in summer. Glob. Biogeochem. Cycles 20.

Chen, C.C., Gong, G.C., Shiah, F.K., 2007. Hypoxia in the East China Sea: one of the largest coastal low-oxygen areas in the world. Mar. Environ. Res. 64, 399-408.

Chu, Z.X., Zhai, S.K., Lu, X.X., Liu, J.P., Xu, J.X., Xu, K.H., 2009. A quantitative assessment of human impacts on decrease in sediment flux from major Chinese rivers entering the western Pacific Ocean. Geophys. Res. Lett. 36.

Chuang, W.-S., Li, H.-W., Tang, T., Wu, C.-K., 1993a. Observations of the countercurrent on the inshore side of the Kuroshio northeast of Taiwan. J. Oceanogr. 49, 581-592.

Chuang, W.S., Li, H.W., Tang, T.Y., Wu, C.K., 1993b. Observations of the countercurrent on the inshore side of the Kuroshio northeast of Taiwan. J. Oceanogr. 49, 581-892.

Chung, S.-W., Jan, S., Liu, K.-K., 2001. Nutrient fluxes through the Taiwan Strait in spring and summer 1999. J. Oceanogr. 57, 47-53.

Egbert, G.D., Erofeeva, S.Y., 2002. Efficient inverse modeling of barotropic ocean tides. J. Atmos. Ocean Technol. 19, 183-204.

Fan, X.P., Zhou, F., Chen, X.E., Huang, D.J., Pohlmann, T., 2011. The influence of the Three-Gorges Dam on hydrographic and hydrodynamic conditions of the East China Sea. Acta Oceanol. Sin. 30, 45-55.

Fang, T.H., 2004. Phosphorus speciation and budget of the East China Sea. Cont. Shelf Res. 24, 1285-1299.

Gong, G.C., Chen, Y.L.L., Liu, K.K., 1996. Chemical hydrography and chlorophyll a distribution in the East China Sea in summer: implications in nutrient dynamics. Cont. Shelf Res. 16, 1561-1590.

Gong, G.C., Wen, Y.H., Wang, B.W., Liu, G.J., 2003. Seasonal variation of chlorophyll a concentration, primary production and environmental conditions in the subtropical East China Sea. Deep-Sea Res. II 50, 1219-1236.

Gong, G.C., Liu, K.K., Chiang, K.P., Hsiung, T.M., Chang, J., Chen, C.C., Hung, C.C., Chou, W.C., Chung, C.C., Chen, H.Y., Shiah, F.K., Tsai, A.Y., Hsieh, C.H., Shiao, J.C., Tseng C.M., Hsu, S.C., Lee, H.J., Lee, M.A., Lin, I.I., Tsai, F.J., 2011. Yangtze River floods enhance coastal ocean phytoplankton biomass and potential fish production. Geophys. Res. Lett. 38.

Guan, B.X., Fang, G.H., 2006. Winter counter-wind currents off the southeastern China coast: a review. J. Oceanogr. 62, 1-24.

Han, A.Q., Dai, M.H., Kao, S.J., Gan, J.P., Li, Q., Wang, L.F., Zhai, W.D., Wang, L., 2012. Nutrient dynamics and biological consumption in a large continental shelf system under the influence of both a river plume and coastal upwelling. Limnol. Oceanogr. 57, 486-502.

He, L., Li, Y., Zhou, H., Yuan, D.L., 2010. Variability of cross-shelf penetrating fronts in the East China Sea. Deep-Sea Res. II 57, 1820-1826.

Hsueh, Y., Wang, J., Chern, C.S., 1992. The intrusion of the Kuroshio across the Continental-Shelf Northeast of Taiwan. J. Geophys. Res. Oceans 97, 14323-14330.

Hu, D.X., 1984. Upwelling and sedimentation dynamics. Chin. J. Oceanol. Limnol. 2, $12-19$.

Hu, D.X., 1994. Some striking features of circulation in the Huanghai Sea and East China Sea. In: Zhou, D., et al. (Ed.), Oceanology of China Seas, Vol. 1. Kluwer Academic Publishers, Dordrecht, Netherlands, pp. 27-38.

Hu, X.M., Xiong, X.J., Qiao, F.L., Guo, B.H., Lin, X.P., 2008. Surface current field and seasonal variability in the Kuroshio and adjacent regions derived from satellitetracked drifter data. Acta Oceanol. Sin. 27, 11-29.

Hu, J.Y., Kawamura, H., Li, C.Y., Hong, H.S., Jiang, Y.W., 2010. Review on current and seawater volume transport through the Taiwan Strait. J. Oceanogr. 66, 591-610.

Ichikawa, H., Beardsley, R., 2002. The current system in the Yellow and East China Seas. J. Oceanogr. 58, 77-92.

Isobe, A., 2008. Recent advances in ocean-circulation research on the Yellow Sea and East China Sea shelves. J. Oceanogr. 64, 569-584.

Johns, W.E., Lee, T.N., Zhang, D.X., Zantopp, R., Liu, C.T., Yang, Y., 2001. The Kuroshio east of Taiwan: moored transport observations from the WOCE PCM-1 array. J. Phys. Oceanogr. 31, 1031-1053.

Kim, H.C., Yamaguchi, H., Yoo, S., Zhu, J., Okamura, K., Kiyomoto, Y., Tanaka, K., Kim, S.W., Park, T., Oh, I., Ishizaka, J., 2009. Distribution of Changjiang diluted water detected by satellite chlorophyll-a and its interannual variation during 1998-2007. J. Oceanogr. 65, 129-135.

Li, D.J., Zhang, J., Huang, D.J., Wu, Y., Liang, J., 2002. Oxygen depletion off the Changjiang (Yangtze River) Estuary. Sci. China Ser. D 45, 1137-1146.

Liu, K.K., Gong, G.C., Lin, S., Yang, C.Y., Wei, C.L., Pai, S.C., Wu, C.K., 1992. The year-round upwelling at the shelf break near the northern tip of Taiwan as evidenced by chemical hydrography. Terr. Atmos. Ocean. Sci. 3, 243-276.

Liu, K.K., Tang, T.Y., Gong, G.C., Chen, L.Y., Shiah, F.K., 2000. Cross-shelf and along-shelf nutrient fluxes derived from flow fields and chemical hydrography observed in the southern East China Sea off northern Taiwan. Cont. Shelf Res. 20, 493-523.

Lv, X.G., Qiao, F.L., Xia, C.S., Zhu, J.R., Yuan, Y.L., 2006. Upwelling off Yangtze River estuary in summer. J. Geophys. Res. Oceans 111.

Lv, X.G., Qiao, F.L., Xia, C.S., Yuan, Y.L., 2007. Tidally induced upwelling off Yangtze River estuary and in Zhejiang coastal waters in summer. Sci. China Ser. D 50, 462-473.

Marchesiello, O., McWilliams, J.C., Shchepetkin, A., 2001. Open boundary condition for long-term integration of regional oceanic models. Ocean Model. 3, 1-21.

Piao, S.L., Ciais, P., Huang, Y., Shen, Z.H., Peng, S.S., Li, J.S., Zhou, L.P., Liu, H.Y., Ma, Y.C., Ding, Y.H., Friedlingstein, P., Liu, C.Z., Tan, K., Yu, Y.Q., Zhang, T.Y., Fang, J.Y., 2010. The impacts of climate change on water resources and agriculture in China. Nature 467, 43-51.

Qiao, F.L., Yang, Y.Z., Lv, X.G., Xia, C.S., Chen, X.Y., Wang, B.D., Yuan, Y.L., 2006. Coastal upwelling in the East China Sea in winter. J. Geophys. Res. Oceans 111.

Qiu, B., Imasato, N., 1990. A numerical study on the formation of the Kuroshio counter current and the Kuroshio branch current in the East China Sea. Cont. Shelf Res. 10 165-184.

Shchepetkin, A.F., McWilliams, J.C., 2005. The regional oceanic modeling system (ROMS): a split-explicit, free-surface, topography-following-coordinate oceanic model. Ocean Model. 9, 347-404.

Stramma, L., Johnson, G.C., Sprintall, J., Mohrholz, V., 2008. Expanding oxygenminimum zones in the tropical oceans. Science 320, 655-658.

Su, J.L., Pan, Y.Q., Liang, X.S., 1994. Kuroshio intrusion and Taiwan Warm current. In: Zhou, D., et al. (Ed.), Oceanology of China Seas, Vol 1. Kluwer Academic Publishers, Dordrecht, Netherlands, pp. 59-77.

Tang, T.Y., Hsueh, Y., Yang, Y.J., Ma, J.C., 1999. Continental slope flow northeast of Taiwan. J. Phys. Oceanogr. 29, 1353-1362.

Tang, T.Y., Tai, J.H., Yang, Y.J., 2000. The flow pattern north of Taiwan and the migration of the Kuroshio. Cont. Shelf Res. 20, 349-371.

Wang, B., Wang, X., 2007a. Chemical hydrography of coastal upwelling in the East China Sea. Chin. J. Oceanol. Limnol. 25, 16-26.

Wang, B.D., Wang, X.L., 2007b. Chemical hydrography of coastal upwelling in the East China Sea. Chin. J. Oceanol. Limnol. 25, 11.

Wang, J.H., Wu, J.Y., 2009. Occurrence and potential risks of harmful algal blooms in the East China Sea. Sci. Total Environ. 407, 4012-4021.

Wang, D.F., He, X.Q., Fang, G., Pan, D.L., 2004. The Design and Construction of a Satellite Data Processing System for Marine Application: Sensors, Systems, and Nextgeneration Satellites VIII, 5570, pp. 602-611.

Wang, K., Cheng, J., Jin, H., Chen, F., Li, H., Gao, S., Lu, Y., 2011. The four seasons nutrients distribution in Changjiang River Estuary and its adjacent East China Sea. J. Mar. Sci. 18-35 (in Chinese with English abstract).

Wei, H., He, Y.C., Li, Q.J., Liu, Z.Y., Wang, H.T., 2007. Summer hypoxia adjacent to the Changjiang Estuary. J. Mar. Syst. 67, 292-303.

Wong, G.T.F., Pai, S.C., Liu, K.K., Liu, C.T., Chen, C.T.A., 1991. Variability of the chemical hydrography at the frontal region between the East-China-Sea and the Kuroshio North-East of Taiwan. Estuar. Coast. Shelf Sci. 33, 105-120.

Wong, G.T.F., Gong, G.C., Liu, K.K., Pai, S.C., 1998. 'Excess nitrate' in the East China Sea Estuar. Coast. Shelf Sci. 46, 411-418.

Wong, G.T.F., Chao, S.Y., Li, Y.H., Shiah, F.K., 2000. The Kuroshio edge exchange processes (KEEP) study - an introduction to hypotheses and highlights. Cont. Shelf Res. 20, 335-347.

Yang, D., Yin, B., Liu, Z., Feng, X., 2011. Numerical study of the ocean circulation on the East China Sea shelf and a Kuroshio bottom branch northeast of Taiwan in summer. J. Geophys. Res. 116, C05015 (doi:05010.01029/02010JC006777).

Yang, D., Yin, B., Liu, Z., Bai, T., Qi, J., Chen, H., 2012. Numerical study on the pattern and origins of Kuroshio branches in the bottom water of southern East China Sea in summer. J. Geophys. Res. 117, C02014.

Zhang, J., Liu, S.M., Ren, J.L., Wu, Y., Zhang, G.L., 2007. Nutrient gradients from the eutrophic Changjiang (Yangtze River) Estuary to the oligotrophic Kuroshio waters and re-evaluation of budgets for the East China Sea Shelf. Prog. Oceanogr. 74, 449-478.

Zhang, J., Gilbert, D., Gooday, A.J., Levin, L., Naqvi, S.W.A., Middelburg, J.J., Scranton, M., Ekau, W., Pena, A., Dewitte, B., Oguz, T., Monteiro, P.M.S., Urban, E., Rabalais, N.N. Ittekkot, V., Kemp, W.M., Ulloa, O., Elmgren, R., Escobar-Briones, E., Van der Plas, A.K., 2010. Natural and human-induced hypoxia and consequences for coastal areas: synthesis and future development. Biogeosciences 7, 1443-1467.

Zhao, B.R., Ren, G.F., Cao, D.M., Yang, Y.L., 2001. Characteristics of the ecological environment in upwelling area adjacent to the Changjiang River estuary. Oceanol. Limnol. Sin. 32, 327-333 (in Chinese with English abstract).

Zhu, Z.Y., Zhang, J., Wu, Y., Zhang, Y.Y., Lin, J., Liu, S.M., 2011. Hypoxia off the Changjiang (Yangtze River) Estuary: oxygen depletion and organic matter decomposition. Mar. Chem. 125, 108-116. 